\title{
Unit mechanisms of fission gas release: Current understanding and future needs
}

\author{
Michael Tonks a, b, *, David Andersson c, Ram Devanathan ${ }^{\mathrm{d}}$, Roland Dubourg e, \\ Anter El-Azab ${ }^{\mathrm{f}}$, Michel Freyss ${ }^{\mathrm{g}}$, Fernando Iglesias ${ }^{\mathrm{h}}$, Katalin Kulacsy ${ }^{\mathrm{i}}$, Giovanni Pastore ${ }^{\mathrm{j}}$, \\ Simon R. Phillpot ${ }^{\mathrm{b}}$, Michael Welland ${ }^{\mathrm{k}}$
}

${ }^{a}$ Department of Mechanical and Nuclear Engineering, Pennsylvania State University, University Park, PA, 16802, USA

${ }^{\mathrm{b}}$ Department of Materials Science and Engineering, University of Florida, Gainesville, FL, 32611, USA

${ }^{\mathrm{c}}$ MST-8, Los Alamos National Laboratory, Los Alamos, NM, 87545, USA

d Energy and Environment Directorate, Pacific Northwest National Laboratory, Richland, WA, 99352, USA

e Institut de Radioprotection et de sureté Nucléaire (IRSN), PSN-RES, Cadarache, St-Paul Lez Durance, France

${ }^{\mathrm{f}}$ School of Materials Engineering, Purdue University, West Lafayette, IN, 47907, USA

g CEA, DEN, DEC, Centre de Cadarache, 13108, Saint-Paul-lez-Durance, France

${ }^{\mathrm{h}}$ CANDESCO, Division of Kinectrics Inc., Toronto, M5E 1S2, Canada

${ }^{\mathrm{i}}$ Fuel and Reactor Materials Department, Centre for Energy Research, Hungarian Academy of Sciences, P.O. Box 49, H-1525, Budapest, Hungary

${ }^{\mathrm{j}}$ Fuel Modeling and Simulation, Idaho National Laboratory, Idaho Falls, ID, 83415, USA

${ }^{\mathrm{k}}$ Computational Techniques, Canadian Nuclear Laboratories, Chalk River, Ontario, K0J 1J0, Canada

\section{A R T I C L E I N F O}

\section{Article history:}

Received 22 September 2017

Received in revised form

10 February 2018

Accepted 9 March 2018

Available online 16 March 2018

\begin{abstract}
A B S T R A C T
Gaseous fission product transport and release has a large impact on fuel performance, degrading fuel and gap properties. While gaseous fission product behavior has been investigated with bulk reactor experiments and simplified analytical models, recent improvements in experimental and modeling approaches at the atomistic and mesoscales are beginning to reveal new understanding of the unit mechanisms that define fission product behavior. Here, existing research on the basic mechanisms of fission gas release during normal reactor operation are summarized and critical areas where work is needed are identified. This basic understanding of the fission gas behavior mechanisms has the potential to revolutionize our ability to predict fission product behavior and to design fuels with improved performance. In addition, this work can serve as a model on how a coupled experimental and modeling approach can be applied to understand the unit mechanisms behind other critical behaviors in reactor materials.
\end{abstract}

() 2018 Elsevier B.V. All rights reserved.

\section{Contents}

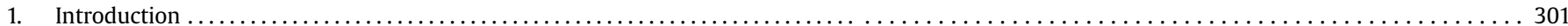

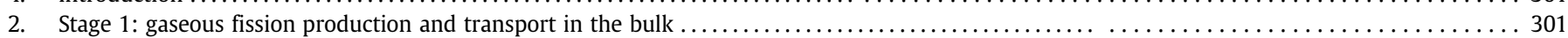

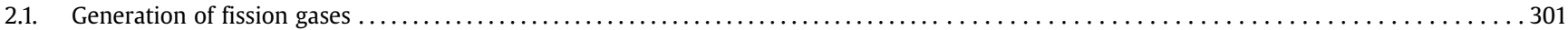

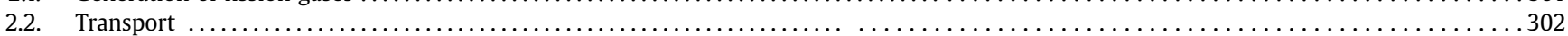

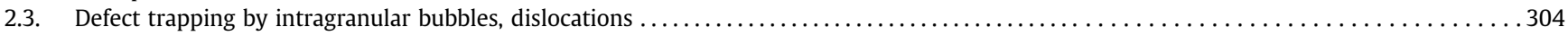

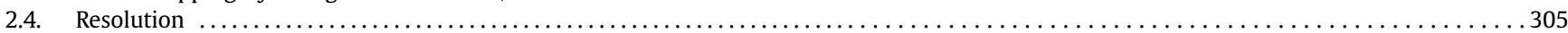

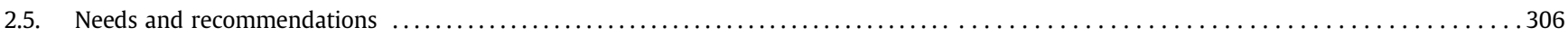

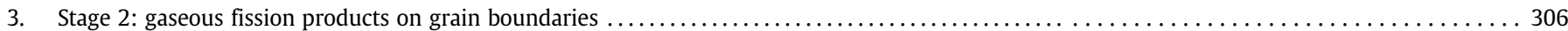

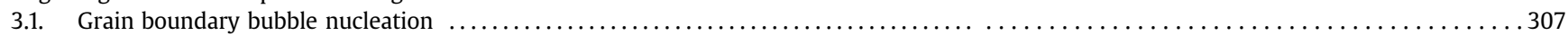

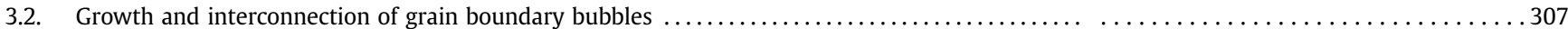

\footnotetext{
* Corresponding author. Department of Materials Science and Engineering, University of Florda, Gainesville, FL, 32611, USA.

E-mail address: michael.tonks@ufl.edu (M. Tonks).
} 


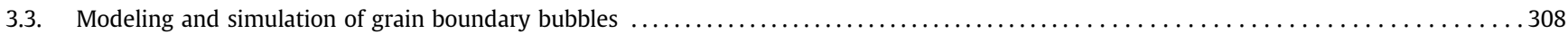

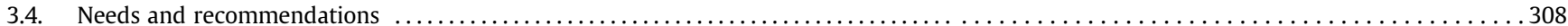

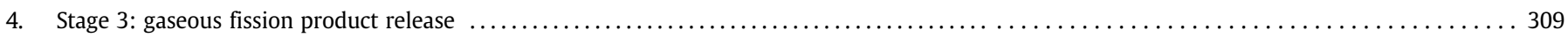

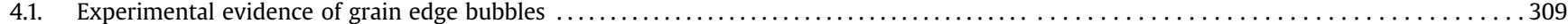

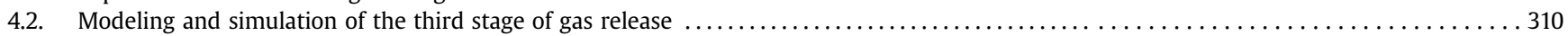

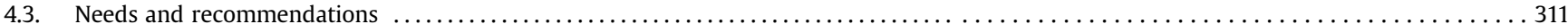

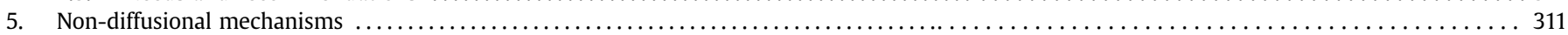

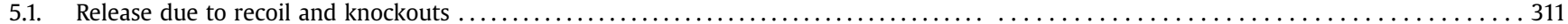

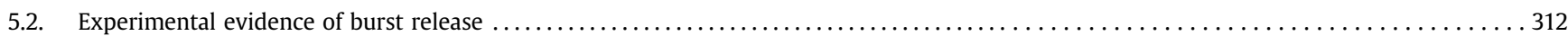

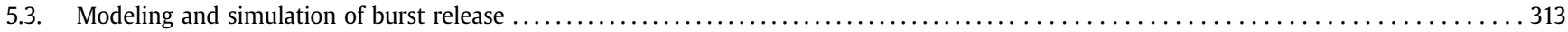

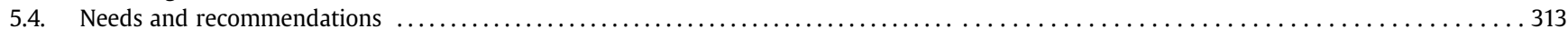

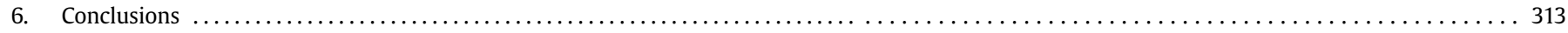

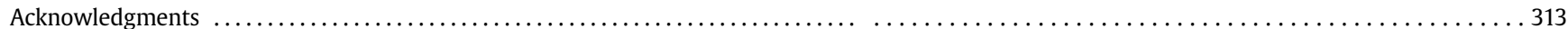

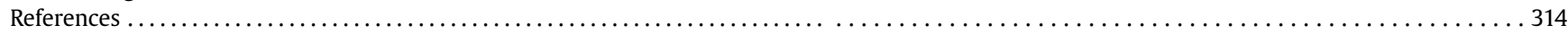

\section{Introduction}

Most present-day commercial Light Water Reactor (LWR) nuclear fuels consist of hermetical zirconium alloy cladding tubes filled with sintered cylindrical $\mathrm{UO}_{2}$ fuel pellets characterized by a granular structure. Approximately $30 \%$ of the fission products created during normal operation are noble gases (xenon and krypton) that dissolve poorly in the $\mathrm{UO}_{2}$ matrix [1,2]; they therefore migrate out of the matrix into pre-existing pores, form bubbles inside and on the boundary of $\mathrm{UO}_{2}$ grains, or ultimately escape to the fuel-to-cladding gap and plenum. The presence of gaseous fission products in the $\mathrm{UO}_{2}$ fuel is detrimental to the thermomechanical properties of the fuel [1]. Furthermore, the release of gaseous fission products from the fuel pellets to the gap is a safety issue for two reasons: fission gases degrade the thermal conductivity of the gap, leading to an increase of fuel center temperature and by positive feed-back to further fission gas release (FGR), as illustrated in Fig. 1, which increases the inner pressure exerted onto the cladding. Second, the fuel pellet is the first barrier preventing the release of fission products to the environment; it is therefore desirable that it retains as much gas as possible. The above reasons make it necessary to better understand gaseous fission product transport and release and possibly enable changes that minimize the escape of fission gases from the pellets to the gap and plenum.

Gas release occurs within $\mathrm{UO}_{2}$ fuel through three stages: first, transport of gas atoms through the bulk of the grain; second, grain face bubble nucleation, growth and interconnection with grain edge bubbles; third, the transport of gas through interconnected grain edge tunnels to free surfaces for release. Fig. 2 illustrates the differences between grain faces and edges, and their corresponding fission gas bubbles. In addition, some gas release can occur due to non-diffusion-based mechanisms. Empirically based and simplified mechanistic models of bulk experiments have been used for decades to predict fission gas release. However, state-of-the-art computational techniques and specific experiments aimed at providing physical parameters to mechanistic models that account for the various stages of gas release have given rise to a multi-scale approach to understanding this behavior. Even with state-of-theart techniques, applying a multiscale approach to understand real fuel behavior is far from trivial.

The present paper is a critical review of the state-of-the art knowledge on the unit mechanisms of fission gas behavior. The scope of the work is restricted to the normal operating conditions and operational transients of commercial $\mathrm{LWR} \mathrm{UO}_{2}$ fuel up to medium burn-ups; the unique aspects of high burn-up will not be reviewed in this work. Special emphasis is given to simulation results and relevant experimental data and their relation to model parameters. In addition, key areas where experimental and simulation work is needed are identified.

\section{Stage 1: gaseous fission production and transport in the bulk}

\subsection{Generation of fission gases}

In $\mathrm{LWR} \mathrm{UO}_{2}$ fuels, fission gases are created from the fission of
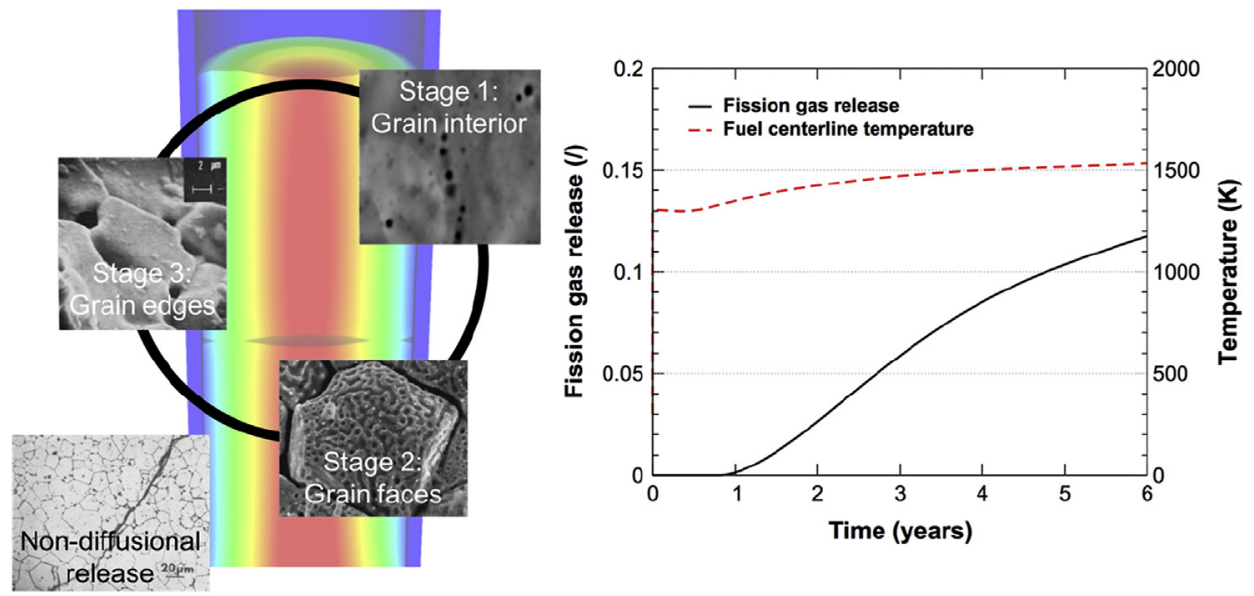

Fig. 1. Illustration of the three stages of diffusional fission gas release and the impact of fission gas release on fuel centerline temperature (taken from Ref. [3]). 


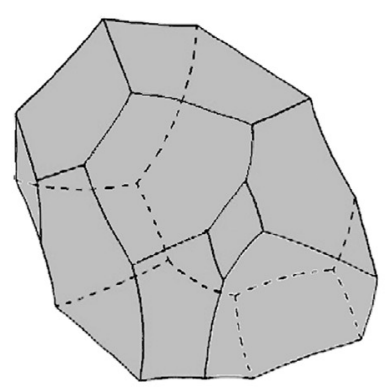

(a)

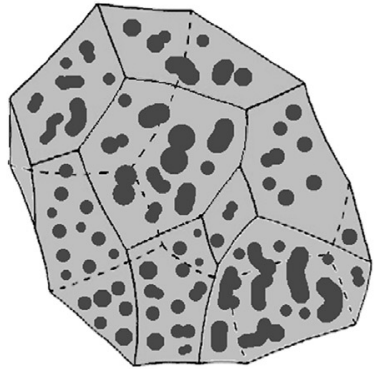

(b)

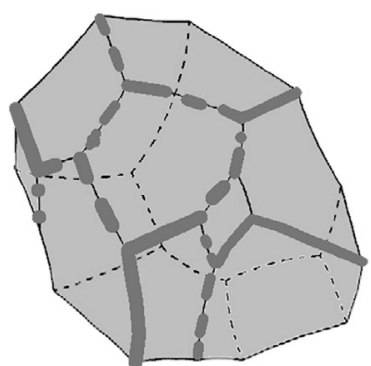

(c)

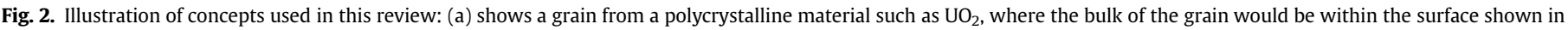

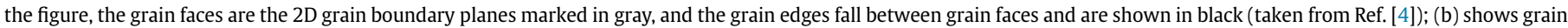
face bubbles that are crucial in stage 2; (c) shows grain edge gas tunnels that are critical in stage 3 and result in gas release to free surfaces.

${ }^{235} \mathrm{U}$ nuclei by thermal neutrons (with kinetic energy around $0.025 \mathrm{eV}$ ) and by the subsequent beta decay of the unstable nuclei created. The fission gases $\mathrm{Kr}$ and $\mathrm{Xe}$ are the most abundant gaseous elements created in $\mathrm{LWR} \mathrm{UO}_{2}$ fuel, with a total yield of around 0.3 atoms/fission; $12.7 \mathrm{wt} \%$ of all fission products are Xe and $1.1 \mathrm{wt} \%$ are $\mathrm{Kr}$ in a $\mathrm{UO}_{2}$ LWR fuel element with $45 \mathrm{GWd} / \mathrm{tU}$ burn-up [5].

Of these two gaseous elements, Xe has the highest fission yield and is found in $\mathrm{UO}_{2}$ LWR fuels with the following isotopic composition (half-life, yield) [6,7]: ${ }^{129} \mathrm{Xe}$ (stable, $0.8 \%$ ), ${ }^{131} \mathrm{Xe}$ (stable, $2.93 \%$ ), ${ }^{132} \mathrm{Xe}$ (stable, $4.38 \%$ ), ${ }^{134} \mathrm{Xe}$ (stable, $8.06 \%$ ) and ${ }^{136} \mathrm{Xe}$ $\left(2.11 \times 10^{21}\right.$ years, $\left.6.46 \%\right) . \mathrm{Kr}$ is found with the following isotopic composition (half-life, yield): ${ }^{83} \mathrm{Kr}$ (stable, $0.54 \%$ ), ${ }^{84} \mathrm{Kr}$ (stable, $1.00 \%),{ }^{85} \mathrm{Kr}$ (10.78 year, $0.29 \%$ ) and ${ }^{86} \mathrm{Kr}$ (stable, 2.02\%). The nuclear reactions leading to the formation of each isotope can be found in Ref. [6]. The most important fission gas isotopes with short halflives are ${ }^{133} \mathrm{Xe}\left(5.25\right.$ days) and ${ }^{135} \mathrm{Xe}(9.1 \mathrm{~h}) .{ }^{135} \mathrm{Xe}$ is easily transmuted into ${ }^{136} \mathrm{Xe}$ by capture of thermal neutrons, making ${ }^{135} \mathrm{Xe}$ a potent neutron-absorbing nuclear poison that can lower the fuel reactivity.

When predicting the quantity of fission gas released to the cladding or trapped in the fuel, it is critical to know the quantity of fission gas atoms produced by irradiation. This is typically computed using the expression $y \dot{F}$, corresponding to the production rate of fission gas in a unit volume of fuel, with $\dot{F}$ the fission rate density of ${ }^{235} \mathrm{U}$ and $y$ the total cumulative yield of the fission gas ( $y$ is usually assumed to be independent of irradiation time).

The ${ }^{235} \mathrm{U}$ fission rate for a given type and design of fuel can be obtained by neutron transport codes. These codes are coupled to nuclear databases, such as JEFF-3 (The Joint Evaluated Fission and Fusion File, OECD-NEA) [8] or ENDF (Evaluated Nuclear Data File, USA) [9], which contain fission cross sections and fission yield values. Fuel performance codes, such as ALCYONE [10], MFPR [11], or BISON [12], usually contain a simplified module (PRODHEL for ALCYONE [13], BONUS for MFPR [14]) for fission rate density calculations, validated against more accurate neutron transport codes [15]. The coupling of fuel performance and neutronics codes is still an area of active research [16,17].

\subsection{Transport}

The underlying timescale for fission gas evolution is determined by the diffusion rate of fission gas atoms in bulk $\mathrm{UO}_{2}[1,18-28]$. The release rate is further modified by interaction with the fuel microstructure, in particular the capture of gas atoms by intragranular bubbles and resolution of gas atoms from these bubbles due to the impact of fission fragments [18,19]. The latter effects are typically modeled based on a coupled set of rate equations that define an effective fission gas diffusion coefficient from the unperturbed bulk diffusion rate and the capture and resolution rates from bubbles $[18,19,23]$. In this section, transport refers to unperturbed diffusion in the bulk lattice; interaction with fission gas bubbles or other sinks is discussed later.

The basic fission gas diffusion properties are determined by the location of gas atoms in the lattice and the interaction with thermal and irradiation induced defects. Many studies employing density functional theory (DFT) [29-42] and molecular dynamics (MD) with empirical potentials [28,29,43-49] have shown that large fission gas atoms such as Xe prefer uranium vacancy trap sites. In most cases this is accompanied by additional oxygen vacancies, though the detailed balance is a function of the oxygen chemical potential or non-stoichiometry, represented as the $\mathrm{x}$ in $\mathrm{UO}_{2 \pm \mathrm{x}}$ $[30,40,41,46]$. See Fig. 3 for an example configuration from a DFT calculation. DFT and empirical potential calculations generally agree that the preferred Xe trap site is a bound Schottky defect (one uranium and two oxygen vacancies) for $\mathrm{UO}_{2-\mathrm{x}}$, a divacancy for $\mathrm{UO}_{2}$ (one uranium and one oxygen vacancy), though the trivacancy is quite close in energy, and a single uranium vacancy for $\mathrm{UO}_{2+\mathrm{x}}$. Since $\mathrm{UO}_{2}$ is a semiconductor, characterization of trap sites and other defects must also specify the charge state, i.e., the number of bound holes or electrons, which is determined by the position of the Fermi level $[30,41,42]$. The Fermi level varies with both temperature and doping concentration (predominantly the oxygen nonstoichiometry). For $\mathrm{UO}_{2-\mathrm{x}}$ and $\mathrm{UO}_{2}$ all trap sites are fully charged (no bound holes), while partial charges may be present in the

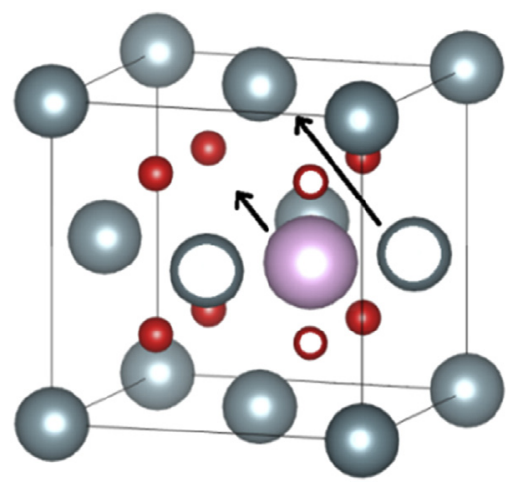

Fig. 3. Migration mechanism of a $\mathrm{Kr}$ atom trapped in a Schottky defect in $\mathrm{UO}_{2}$ involving an additional uranium vacancy. Uranium ions are shown in green, oxygen in red, krypton in purple and vacancies in empty circles. Taken from Ref. [41]. (For interpretation of the references to colour in this figure legend, the reader is referred to the Web version of this article.) 
Table 1

Xe solution energies in $\mathrm{UO}_{2+\mathrm{x}}$. The subscripts denote the type of trap site. EP refers to static empirical potential calculations.

\begin{tabular}{llll}
\hline Trap site type & EP [43,44] & DFT [40] & DFT [31] \\
\hline $\mathrm{UO}_{2-\mathrm{x}}$ & & & \\
$\mathrm{Xe}_{\mathrm{O}}$ & 13.34 & 9.61 & 11.19 \\
$\mathrm{Xe}_{\mathrm{U}}$ & 18.32 & 9.89 & 7.37 \\
$\mathrm{Xe}_{\mathrm{UO}}$ & 12.93 & 6.27 & 5.78 \\
$\mathrm{Xe}_{\mathrm{UO2}}$ & 9.57 & 3.88 & \\
$\mathrm{Xe}_{\mathrm{U} 2 \mathrm{O} 2}$ & 19.78 & & \\
$\mathrm{Xe}_{\mathrm{I}}$ & 17.23 & 11.10 & \\
$\mathrm{UO}_{2}$ & & & 6.93 \\
$\mathrm{Xe}_{\mathrm{O}}$ & 16.75 & 11.48 & 5.24 \\
$\mathrm{Xe}_{\mathrm{U}}$ & 11.50 & 6.13 & \\
$\mathrm{Xe}_{\mathrm{UO}}$ & 9.52 & 4.40 & \\
$\mathrm{Xe}_{\mathrm{UO2}}$ & 9.57 & 3.88 & \\
$\mathrm{Xe}_{\mathrm{U} 202}$ & 12.96 & & \\
$\mathrm{Xe}_{\mathrm{I}}$ & 17.23 & 11.10 & \\
$\mathrm{UO}_{2+\mathrm{x}}$ & & & \\
$\mathrm{Xe}_{\mathrm{O}}$ & 20.16 & 13.25 & 3.11 \\
$\mathrm{Xe}_{\mathrm{U}}$ & 4.68 & 2.61 & \\
$\mathrm{Xe}_{\mathrm{UO}}$ & 6.11 & 2.63 & \\
$\mathrm{Xe}_{\mathrm{UO} 2}$ & 9.57 & 3.88 & \\
$\mathrm{Xe}_{\mathrm{U} 2 \mathrm{O} 2}$ & 6.13 & 11.10 & \\
$\mathrm{Xe}_{\mathrm{I}}$ & 17.23 & & \\
\hline
\end{tabular}

$\mathrm{UO}_{2+\mathrm{x}}$ regime. Recently, this computational prediction of $\mathrm{Kr}$ and $\mathrm{Xe}$ location in Schottky defects in $\mathrm{UO}_{2}$ was experimentally confirmed in Refs. [50,51] by X-ray Absorption Spectroscopy. Table 1 summarizes some of the calculated Xe solution energies, which measure the preference for various trap sites (the solution energy is equal to the trap formation energy and the incorporation energy of the fission gas atoms in the trap site). This table lists the solution energy, while a comprehensive analysis should also include the entropy contributions [41,42]; however the preferred trap site obtained from the full analysis is generally the same as that obtained from the energy alone [41]. The absolute values depend on the reference state of, e.g., the fission gas atom and different choices reference state choices prevent direct comparison between studies, though the relative ordering is not affected by the reference state and exhibit consistent trends between most calculations.

Although interstitial Xe diffusion is rapid [31], its high-energy state compared to vacancy trap sites leads to negligible contribution to thermal or intrinsic diffusion (out-of-pile). This is likely also the case for in-pile conditions. However, $\mathrm{Kr}$ interstitials have been shown to be important for highly reducing conditions [41], for which the availability of vacancies is strongly decreased. For other conditions, fission gas diffusion occurs through vacancy mechanisms involving at least one additional uranium vacancy bound to the Xe (or Kr) vacancy trap sites. The binding energy of the second assisting uranium vacancy is negative for all clusters and in many cases forms a very stable complex with the original trap site $[30,42,45,46]$. The fission gas atom easily moves between the two vacancies of the mobile cluster and in most cases the Xe atom even occupies the central position of the cluster, i.e., in-between the two constituent U vacancies [29,30,44,45]. The rate-limiting step for Xe diffusion is migration of one of the vacancies to another nextnearest neighbor position, which can either occur by a direct migration jump or by traversing over a second nearest neighbor position [29,42]. A similar mechanism has been identified for $\mathrm{Kr}$ [41]. The resulting diffusivity can be expressed in terms of the effective vacancy formation energy, the binding energy to the trap site and the cluster migration barrier [30,41,42,44,46]. Refined models may take into account additional atomic jumps within the cluster to properly define the diffusion correlation factor [41]. A complete analysis of diffusion should account for migration of each mobile cluster and then weigh them according to the concentration in the lattice. In practice, this can be captured by adding an additional term to the activation energy for diffusion that measures the cluster stability with respect to the most favorable trap site. Defect formation energies (enthalpies), migration barriers, and binding energies (enthalpies) can be calculated from DFT, while the corresponding entropies are more challenging for DFT calculations and have so far only been investigated using calculations based on empirical potentials $[41,42,52]$. The resulting diffusivities increase going from $\mathrm{UO}_{2-\mathrm{x}}$, to $\mathrm{UO}_{2}$ and $\mathrm{UO}_{2+\mathrm{x}}[41,42,44]$. This is a consequence of both an increase in the concentration of uranium vacancies and a reduction in the migration barrier of clusters involving fewer oxygen vacancies, though the latter effect is at least partially counteracted by a reduction in the vacancy binding energy. Table 2 summarizes calculated Xe activation energies and compares the results to available experimental data. Where available, pre-exponential factors are also listed.

Experimental data on fission gas diffusion coefficients primarily rely on measuring the gas release in post-irradiation annealing experiments. As a result, the uncertainty of the fission gas diffusion coefficient as function of temperature is quite high [54], and is usually ascribed to variations in the sample non-stoichiometry, which is very sensitive to the experimental conditions. The sample non-stoichiometry is controlled by the temperature and the chemistry of the experimental setup, for example, whether the measurement was carried out in vacuum or in flowing $\mathrm{H}_{2}$ gas, and the material used for the sample holder. Xe diffusion studies on nominally stoichiometric $\mathrm{UO}_{2}$ yield activation energies from $2.87 \mathrm{eV}$ to $3.95 \mathrm{eV}$ and pre-exponential factors from $5 \times 10^{-4} \mathrm{~m}^{2} / \mathrm{s}$ to $2.90 \times 10^{-12} \mathrm{~m}^{2} / \mathrm{s}$ [42]. Typically, higher activation energy is

Table 2

$\mathrm{Xe}$ and $\mathrm{Kr}$ activation energies and pre-exponential factors for fission gas diffusion in $\mathrm{UO}_{2 \pm \mathrm{x}}$. EP refers to static empirical potential calculations.

\begin{tabular}{|c|c|c|c|c|}
\hline Calculated Properties & DFT \& EP [42] & EP [46] & DFT \& EP [41] & $\operatorname{Exp}[53]$ \\
\hline \multicolumn{5}{|l|}{$\mathrm{UO}_{2-\mathrm{x}}$} \\
\hline $\mathrm{Xe} \Delta \mathrm{H}(\mathrm{eV})$ & 6.39 & 6.5 & & $6.0 \pm 0.1$ \\
\hline $\mathrm{Xe} \mathrm{D}_{0}\left(\mathrm{~m}^{2} / \mathrm{s}\right)$ & $2.06 \times 10^{-3}$ & & & $4 \times 10^{-2} 1.6 \times 10^{1}$ \\
\hline $\mathrm{Kr} \Delta \mathrm{H}(\mathrm{eV})$ & & & 9.54 & \\
\hline $\mathrm{Kr} \mathrm{D}\left(\mathrm{m}^{2} / \mathrm{s}\right)$ & & & $5.35 \times 10^{-8}$ & \\
\hline \multicolumn{5}{|l|}{$\mathrm{UO}_{2}$} \\
\hline $\mathrm{Xe} \Delta \mathrm{H}(\mathrm{eV})$ & 3.94 & 4.0 & & $3.9 \pm 0.4$ \\
\hline $\mathrm{Xe} \mathrm{D}_{0}\left(\mathrm{~m}^{2} / \mathrm{s}\right)$ & $3.17 \times 10^{-9}$ & & & $5 \times 10^{-6}-5 \times 10^{-4}$ \\
\hline $\mathrm{Kr} \Delta \mathrm{H}(\mathrm{eV})$ & & & 5.27 & \\
\hline $\mathrm{Kr} \mathrm{D}\left(\mathrm{m}^{2} / \mathrm{s}\right)$ & & & $7.08 \times 10^{-9}$ & \\
\hline \multicolumn{5}{|l|}{$\mathrm{UO}_{2+\mathrm{x}}$} \\
\hline $\mathrm{Xe} \Delta \mathrm{H}(\mathrm{eV})$ & $1.71-2.73$ & 2.4 & & $1.7 \pm 0.4$ \\
\hline $\mathrm{Xe} \mathrm{D}_{0}\left(\mathrm{~m}^{2} / \mathrm{s}\right)$ & $1.19 \times 10^{-13}-2.21 \times 10^{-8}$ & & & $1 \times 10^{-12}-1 \times 10^{-8}$ \\
\hline $\mathrm{Kr} \Delta \mathrm{H}(\mathrm{eV})$ & & & 0.73 & \\
\hline $\mathrm{Kr} \mathrm{D}\left(\mathrm{m}^{2} / \mathrm{s}\right)$ & & & $3.07 \times 10^{-7}$ & \\
\hline
\end{tabular}


compensated by a higher pre-exponential factor, which is expected since the stoichiometry is maintained close to $\mathrm{UO}_{2}$ for all cases. In order to systematically explore the variation of the diffusivity with non-stoichiometry, experiments have been performed under the same initial irradiation conditions for samples in the $\mathrm{UO}_{2-\mathrm{x}}, \mathrm{UO}_{2}$ and $\mathrm{UO}_{2+\mathrm{x}}$ (non-)stoichiometry ranges. These experiments established clear trends for the three ranges, which provide data suitable for validation of atomistic simulations. Most calculations qualitatively capture the variation in the diffusivity as function of nonstoichiometry, though there are still questions as to the quantitative agreement. The foremost reason for this uncertainty is that DFT cannot model $\mathrm{UO}_{2}$ without the addition of an empirical energy function, commonly referred to as "+U", that is implemented either using the Local Density Approximation (LDA + U) [55] or the Generalized Gradient Approximation (GGA + U) [56]. There is a difference in the cluster migration barriers predicted by LDA $+\mathrm{U}$ and GGA + U calculations, which can be traced back to the difference in equilibrium lattice volumes [30,57]. This gives rise to a spread in the predicted activation energies of up to $1 \mathrm{eV}$. Defect formation energies are, however, quite similar between the two DFT approaches [30]. Nevertheless, the complexity of the $\mathrm{UO}_{2}$ electronic structure also gives rise to uncertainties in the calculated thermodynamic properties. Moreover, in order to compare to experiments the correct thermodynamic conditions must be applied, which is a hard problem and, in many cases, we do not know the exact experimental conditions, making comparison difficult.

In FGR models the intrinsic diffusion coefficient discussed so far is used at high temperature (above approximately $1600 \mathrm{~K}$ ). At lower temperatures, the annealing of radiation damage is no longer complete and the increased concentration of point defects must be accounted for [22], both in terms of assisting uranium vacancies and as a potential shift in the preferred trap site for fission gases. This gives rise to radiation-enhanced diffusion dominating over intrinsic diffusion in an intermediate temperature range (from about 1300 to $1600 \mathrm{~K}$ ). The activation energy has been derived from a rate theory model of the concentration of radiation-induced vacancies (proportional to the square root of the fission rate) and the assumption that the rate-limiting step for Xe transport is diffusion of uranium vacancies, which gives an activation energy that is much lower than in the intrinsic regime and a very low preexponential factor. Atomistic simulations are presently not able to reproduce this behavior, as the mobility predicted by DFT and empirical potential calculations for the defect clusters examined to date is too low [42,52]. This discrepancy may be a consequence of neglecting the mobility of extended Xe-vacancy clusters, i.e. clusters involving more than one bound uranium vacancy and additional oxygen vacancies, or possibly Xe interstitials which are known to be highly mobile but also energetically very unfavorable. Uranium divacancies form under irradiation and they migrate with a much lower barrier than single uranium vacancies, quickly contributing to the overall diffusivity. A similar mechanism could be active for Xe trap sites if they bind a sufficient number of uranium vacancies to enable cluster migration according to a fast uranium divacancy mechanism instead of a slower single vacancy mechanism. This hypothesis implies that, in order to develop accurate models of Xe diffusion under irradiation, it is critical to understand the interaction between Xe and vacancies leading to the formation of extended clusters with potentially increased mobility. As the extended clusters grow to form small bubbles, the mobility is expected to decrease. There is still significant uncertainty in the theoretical analysis of radiation-enhanced diffusion; additional work is required to resolve these issues. Below about $1300 \mathrm{~K}, \mathrm{Xe}$ diffusion is athermal and driven directly by irradiation damage processes. MD simulations have captured this behavior with rather good accuracy [49].

\subsection{Defect trapping by intragranular bubbles, dislocations}

The solubility of fission gases in the $\mathrm{UO}_{2}$ matrix is very low and the incorporation of fission gases is highly connected to the characteristics of the point defects in which their incorporation might be possible. Because the calculated incorporation energies are positive (less positive in large Schottky defects), which means that the fission gas atoms are not stable in the fuel matrix in isolated defects. This will induce a tendency for fission gases to be easily trapped in more stable configurations in various clusters or sinks, the precipitation of gases into bubbles being one of the main examples as well as trapping on dislocations or at grain boundaries.

Experimental evidences of in-reactor or in-pile intragranular bubble formation and growth have been reported in numerous references, including the initial works of Turnbull [58], Cornell et al. [59], and Baker [60]. More recently, Kashibe et al. [61] and Nogita and Une [62,63] reported similar observations. Typically, the diameter of the intragranular bubbles ranges from one to $10 \mathrm{~nm}$, and their density is about $10^{23} \mathrm{~m}^{-3}$, with a narrow size distribution. The bubbles size increases and their concentration decreases slightly with increasing temperature and burn-up or with decreasing fission rate.

At higher burn-ups and/or temperatures a second bubble population is created $\left(20-100 \mathrm{~nm}\right.$ in size, $10^{21} \mathrm{~m}^{-3}$ in density), often located at dislocations $[64,65]$. At high temperatures, these bubbles are surrounded by a very high density of tiny bubbles (mean diameter less than $10 \mathrm{~nm}$ ), and there exist large areas completely free of bubbles $[60,66]$. The bubbles are often found in contact with similar size so-called $\varepsilon$-phase particles containing the noble metals molybdenum, ruthenium, palladium, technetium, and rhodium.

The intragranular bubbles are facetted (the (111) plan is favored), highly pressurized ( 2-4 GPa at ambient temperature) [67] and their size and concentration are, at least partly, controlled by the resolution phenomena described in section 2.4. At high temperature in annealing conditions, bubble coarsening results in the formation of very large bubbles in the center part of the grain and a so-called bubble-denuded zone near grain boundaries $[61,68,69]$.

The mobility of the bubbles is low and the mechanism by which migration occurs depends on the bubble size, moving from surface diffusion to volume diffusion and to evaporation/condensation with increasing bubble size. A quite complete review of bubble mobility is given by Veshchunov [70].

Intragranular bubble nucleation can be homogeneous, occurring within the perfect crystal lattice, or heterogeneous, occurring at segregation sites such as defects. Bubble nucleation is one of the most difficult processes to understand, as it cannot be observed directly. However, several experiments in which $\mathrm{UO}_{2}$ samples have been irradiated and analyzed showed that many of the bubbles were aligned in straight lines [58]. A possible interpretation of these observations is that nucleation takes place in the wake of fission fragments [58,60]. Homogeneous nucleation can be modeled using a two-atom approach, in which gas atom/vacancy clusters migrate and combine, eventually forming bubbles when enough atoms come together. This model is more accurate when additional nucleation sites from extended defects are not in significant concentration. In Ref. [11], a bubble nucleation model is further refined by adding, as a nucleation probability, the vacancy concentration stabilizing gas atoms clustering, following the developments given in Ref. [71]. Recently, a more general model was proposed (applied to fission gases in U-Mo matrix) for a multi-atom gas-bubble nucleation mechanism [72].

Gas bubble growth is also difficult to observe directly. The main mechanisms responsible for bubble growth were reviewed in Ref. [73]. These mechanisms include those related to individual 
bubble growth, such as absorption of gas atoms and vacancies or dislocation loop punching, and those related to increases in the mean bubble size, such as migration-coalescence and Ostwald ripening. Reliable modelling of bubble growth remains a difficult challenge for simplified models. One classical example is gas atom capture by bubbles, often described by assuming the bubbles to be a perfect spherical sink to give a simple relation for the gas atom capture rate. In post-irradiation annealing, this simplified approach leads to a strong overestimation of the capture rate. Another important deficiency of simplified models is the lack of consideration of the effect of point and extended defects on bubble relaxation and growth.

Modern advances in atomic scale simulation and detailed single effect experimental design have facilitated a deeper understanding of bubble formation and behavior [74]. Ion-implanted $\mathrm{UO}_{2}$ samples have proven to be a promising approach for the study of bubble formation. In Refs. [75-77], transmission electron microscopy (TEM) experiments were performed on a set of $\mathrm{UO}_{2}$ thin foils following the implantation of Xe ions. TEM results revealed dislocation and dislocation loop formation, as well as the formation of nanometer-sized Xe aggregates. At concentrations of 0.4 at.\%, Xe precipitation occurred above $870 \mathrm{~K}$. The threshold temperature for Xe precipitation decreased to $670 \mathrm{~K}$ for the higher concentration samples (2 at.\%). The formation of nanometer-sized voids was observed [76] following the ballistic effects of implanted ions, though these voids were unstable without gas atoms. These experimental results were successfully compared to classical MD simulations [78], which showed that heterogeneous nucleation is the most likely. It was preceded by the formation of vacancy clusters in the central part of the collision cascade (whereas interstitial clusters were formed in the external part of the cascade). These vacancy clusters acted as traps for gas atoms, forming the initial nanometer size bubble population. A more classical mechanism of bubble nucleation was simulated in Ref. [79]. In this work, Xe atoms migration through Schottky defects was simulated and it was found that the clustering of these Xe-Schottky defects formed nanometer size bubbles. However, the calculated bubble size was underestimated compared to experimental values and the defect concentration was artificially enhanced in the simulation cell.

Ion-implanted $\mathrm{UO}_{2}$ samples have also been used to investigate the thermodynamic state of bubbles using X-ray absorption experiments [51,67]. In Ref. [67], X-ray absorption near edge spectroscopy (XANES) and Extended X-ray absorption fine structure (EXAFS) measured Xe bubbles pressures of 2-5 GPa at low temperature. When extrapolated to higher temperatures, the high gas pressure could reduce the sink efficiency close to zero, preventing gas atoms capture. These results were confirmed in Ref. [51] for Kr. With 8 at\%, pressurized bubble with solid gas were observed at room temperature, while at $1670 \mathrm{~K}$ a bimodal distribution was observed with larger cavities only partially filled with Kr. For 0.5 at $\%, \mathrm{Kr}$ was found in Schottky defects at room temperature, in highly pressurized bubbles at $1270 \mathrm{~K}$, and in bubbles with a bimodal distribution at $1670 \mathrm{~K}$. Besides these experimental evidences, the MD simulations reported in Ref. [47] gave additional insights. A thermodynamic driving force for bubble nucleation from point defects is highlighted by the substantial reduction in the free energy of Xe atoms contained within larger bubbles, relative to the accommodation at point defects in the lattice. In addition, gas atoms were observed to force the oxygen ions from the bubble surface into the crystal lattice to relieve the pressure inside the cavity. These studies suggest that gas atom capture is prevented in pressurized bubbles.

Bubble growth was exhaustively studied in Ref. [76], varying many possible impacting parameters in ion irradiated samples. This study clearly showed that migration-coalescence is not relevant for intragranular bubble growth, and that growth by atom capture and vacancy absorption is more likely. The study also showed that bubbles grow faster near extended defects such as dislocations or grain boundaries which could act as vacancy sources.

Another significant sink for fission gas atoms are dislocations, and these sinks were recently investigated using MD simulations. Nerikar et al. [80] investigated Xe segregation to edge and screw dislocations (and representative grain boundaries). The segregation trends were found to depend significantly on the dislocation characteristics. Xe prefers to segregate to screw dislocation rather than to edge (segregation energies $5.5 \mathrm{eV}$ and $2.7 \mathrm{eV}$, respectively). The Xe segregation to dislocations is therefore found to be thermodynamically favorable. To go further, Murphy et al. [81] performed MD simulations using empirical potentials of Xe diffusion around edge dislocations in $\mathrm{UO}_{2}$ to establish the importance of this pathway for fission gas release. The results suggest that for isolated atoms near a dislocation, the activation energy for Xe diffusion is dramatically reduced relative to the bulk. However, Xe atoms diffusing along the dislocation aggregate to form small bubbles, which incorporate all of the isolated mobile Xe atoms and inhibits fast diffusion of Xe along the dislocation core.

As discussed above, the behavior of intragranular fission gas bubbles in $\mathrm{UO}_{2}$ is fairly well understood. However, the incorporation of this understanding in modeling is still limited. A simplified description of intragranular bubble behavior is included in fuel performance codes such as ENIGMA [82] and TRANSURANUS [83] and an improved description is used in the more mechanistic approaches taken in BISON [3], MARGARET from ALCYONE [84], and MFPR [11]. Nevertheless, the newer insights, such as those on bubble nucleation and pressure still need to be included.

\subsection{Resolution}

It has been known for more than five decades that thermal and radiation effects can cause changes in the mean size and spatial distribution of fission gas bubbles by resolution into the nuclear fuel matrix. There is considerable interest in reliably estimating resolution under a variety of operating conditions to understand fuel swelling and FGR, leading to pellet-clad interaction, cladding creep and cladding failure.

MacInnes and Brearley developed a simple model [85] for the thermal resolution from intragranular gas bubbles and considered this mechanism as a controlling factor for gas release from fuel subjected to rapid transient heating. They considered thermal resolution as the dominant mechanism over radiation damage (ballistic resolution). Turnbull developed a fission gas model [58] assuming that intragranular bubbles are typically small (radius of $0.5 \mathrm{~nm}$ ) and nucleated along fission tracks, their life is short, and the gas atoms in the bubble are resolved by an encounter with a single fission fragment. This model assumed a uniform distribution of immobile bubbles of $1 \mathrm{~nm}$ radius that merely act as sources and sinks for the gas, which was considered to migrate by single atom diffusion within the fuel matrix. White and Tucker [18] incorporated the ideas of Turnbull [58] to develop an improved fission gas model. Jackson and Catlow [86] used molecular statics with ionic potentials to study single Xe atom trapping and migration. They obtained large energies for solution of gas atoms from underpressurized bubbles and concluded that thermal resolution from them is unlikely.

Olander and Wongsawaeng [87] have reviewed the resolution of fission gas bubbles by two radiation induced mechanisms-heterogeneous involving complete resolution of a bubble by a fission fragment and homogeneous involving the resolution of individual fission gas atoms by collisions with energetic recoils. Models of irradiation-induced resolution that do not specify if the resolution is homogeneous or heterogeneous have also been 
proposed. The minimum energy for homogeneous resolution has been arbitrarily assumed to be $300 \mathrm{eV}$ [88]. Subsequently, Parfitt and Grimes [89] performed MD simulations that showed the minimum energy for homogeneous resolution to be about $56 \mathrm{eV}$. The homogeneous resolution parameter (reciprocal of mean lifetime) was estimated to be two orders of magnitude smaller than the heterogeneous resolution parameter [87]. The heterogeneous nucleation and resolution model fits electron microscopy data for the number density of intragranular bubbles but the estimate of bubble size is off by a factor of $2-4$ relative to experiment [87].

Recent MD simulations have disagreed on the relative roles of homogeneous and heterogeneous resolution. Schwen et al. [90] studied homogeneous resolution from a bubble of radius $1 \mathrm{~nm}$ using Monte Carlo and MD simulations. They obtained a resolution parameter that was lower than previous estimates by a factor of fifty. The same group [91] subsequently combined MD simulation with a two temperature model to study the effect of fission track damage on a similar Xe bubble in $\mathrm{UO}_{2}$. They did not observe complete bubble destruction and concluded that heterogeneous resolution is likely to be insignificant compared to homogeneous resolution of fission gas. In contrast, recent MD simulations of lower energy recoils and higher energy thermal spikes by Govers et al. [92] showed that thermal spikes destroy Xe bubbles completely in $\mathrm{UO}_{2}$ and they are more effective at gas resolution than primary knock on atoms.

Based on the work of Govers et al. [92] and the previous use of a fission-rate based resolution parameter [93], Pastore et al. [3] have performed a sensitivity analysis of fission gas behavior by considering variation of the resolution parameter over two orders of magnitude. The model was incorporated into the BISON fuel performance code [12]. The study showed that engineering scale modeling of fission gas behavior is limited by large uncertainties, which limit the improvement of predictive power by the incorporation of more physical details or the increase of model complexity. To improve the predictive power of fission gas behavior in nuclear fuel, we need to enhance our understanding of the parameters that go into the models and engineering scale codes, and quantify the uncertainties associated with these parameters. DFT calculations and MD simulations are needed to determine important parameters, such as migration energies of vacancies, interstitials and fission gas atoms, defect recombination volumes, interfacial energies, and binding energies of fission gas atoms with point and line defects. These quantities can serve as inputs to phase field models and rate theory calculations.

\subsection{Needs and recommendations}

Though much progress has been made in our understanding of the basic mechanisms governing stage one of fission gas release, there are still many areas in which further work is needed. In this section, we present four open questions that need to be answered in the future using new experimental and modeling and simulation efforts.

The first question that needs to be answered is: how does nonstoichiometry impact the intrinsic diffusion of $\mathrm{Xe}$ in $\mathrm{UO}_{2}$ ? While the impact of stoichiometry has been investigated in the past using experiments and DFT calculations, as discussed above, the comparison between the two is difficult due to uncertainty in the experiment conditions. Thus, new experimental data is needed with carefully controlled sample stoichiometry and environmental conditions. One possible way of doing this would be to measure fission gas release in unirradiated samples in which Xe has been added during sample fabrication, or afterwards using implantation. Then, new calculations would need to be conducted that duplicate the chemistry conditions as closely as possible. The comparison between measured and calculated diffusivities at various nonstoichiometries would provide critical information and would help in validating the simulations.

The second question is: what defects drive the acceleration of diffusion due to radiation at temperatures between 1300 and $1600 \mathrm{~K}$ ? The rapid Xe diffusion that occurs at these temperatures cannot be explained by intrinsic diffusion nor by athermal diffusion fully driven by radiation damage. As discussed previously, some atomistic studies have begun to investigate this, but more work is needed. New experimental data in this regime could provide significant value, but would be very difficult as the diffusion must be measured during irradiation. New simulation approaches to model this behavior that can reach long enough times and large enough spatial resolutions to resolve the extended defects and their impact on this diffusion regime could also provide significant value.

The third question regarding stage one of fission gas release is: what drives the formation of a multimodal intragranular bubble size distribution at higher temperature and burnup? Experimental observation has clearly demonstrated the formation of large intragranular bubbles at high temperatures and burnups, but the driving force for this is unknown. Again, new experimental data could be extremely valuable in answering this question, but obtaining such data would be difficult as post-irradiation annealing would not be sufficient since the samples do not experience resolution. Simulating the formation of the bimodal distribution would also be difficult as long time scales are needed and both small bubbles ( $<10 \mathrm{~nm}$ radius) and large bubbles (between 20 and $100 \mathrm{~nm}$ ) must both be resolved.

The final open question for stage one is: what is the relative importance of homogeneous and heterogeneous resolution of gas atoms from intragranular bubbles? Direct observation of fission gas resolution would be very difficult to achieve experimentally, and efforts using simulation to determine the relative importance of homogeneous and heterogeneous resolution have returned conflicting results. Thus, additional simulations are needed to clarify this important point.

\section{Stage 2: gaseous fission products on grain boundaries}

The migration of fission gases toward grain boundaries is the first stage of FGR. Grain boundaries are structurally and energetically different from the interior of grains and may provide faster diffusion paths for fission gases and serve as regions for heterogeneous nucleation and growth of fission gas bubbles. The second stage, and the subject of this section, is the formation and growth of fission gas bubbles on grain boundaries and their interlinkage by both growth and migration to form paths for FGR to grain edges. A survey of the basic mechanisms related to the role of grain boundaries in fission gas behavior can be found in the classical literature $[1,23,94]$. In recent years, these models have been enriched by refining the related microstructure representation $[18,19,70,95,96]$.

It is generally recognized that transfer of fission gas from grain boundaries to grain edge tunnels is dominated by growth and interconnection of grain boundary bubbles as opposed to grain boundary diffusion. Olander and Van Uffelen [97] assessed the migration distance of a Xe atom in a grain boundary containing a population of traps with characteristics that roughly encompass the grain boundary bubble populations observed in irradiated $\mathrm{UO}_{2}$ fuel. Their finding that gas atoms will be trapped after a migration distance equal to the size of a grain or less provided a theoretical justification for the rejection of grain boundary diffusion as a FGR mechanism in favor of bubble network evolution. Gas release through bubble interconnection has been often represented through a saturation limit for the fraction of grain boundary area 
covered by gas bubbles, or the grain boundary fractional coverage [25,70,98-100].

Several questions come to mind regarding the role of grain boundary bubbles in FGR in $\mathrm{UO}_{2}$ nuclear fuel, which may be summed up as the following: how do the density, size distribution and morphology of grain boundary bubbles evolve during fuel service and how does this evolution facilitate FGR and fuel swelling? The role of grain boundary bubbles in FGR cannot be separated from the role of the matrix and the formation of the final pore network through which fission gases are vented to the grain edge network. In this regard, models for the grain boundary effects are tested together with models for the role of the matrix and the global pore network behavior by comparison with global swelling or FGR data. Most models, however, account for the microstructure through certain idealizations to enable the development of coupled evolution equations that govern the global balance of fission gases along with the fission gas bubble population. The postulated scenarios and microstructure idealizations are evident in the works of White and Tucker [95], Kogai [98], and White [19]. In the latter work, the hypothesis leading to modeling grain boundary bubbles in fission gas swelling and release were supported by Post-Irradiation Examination (PIE) data from the Advanced Gas-cooled Reactor/Halden Ramp Test Programme [101]. This effort showed that the development of mechanistic grain-face swelling models may include: (a) the nucleation of grain boundary bubbles, (b) growth of such bubbles by collecting gas atoms from the surrounding matrix, (c) bubble growth and coalescence and adjustment of bubble morphology by capillarity forces, and (d) bubble connection with grain edges. Fig. 4 shows a typical experimental result that led to these postulates. The role of grain boundary bubbles is evident from part (c) of this figure, where the grain boundary bubbles formed as isolated bubbles in the early state interlink to create long pores connecting most of the grain face with the grain edge pores that mediate the final venting of fission gases.

\subsection{Grain boundary bubble nucleation}

The question of grain boundary bubble nucleation does not seem to be well addressed in the literature. Most authors rather concentrate on size and number density evolution of bubbles via growth and coalescence, with nucleation not being modeled explicitly. Typically an initial number density of bubbles is considered and further nucleation during the irradiation is neglected (one-off nucleation) [19,70,95,98,100]. White [19] proposed that, at an early stage, nucleation of fission gas bubbles occurs uniformly throughout the bulk of the irradiated fuel and that the bubbles nucleating within a bubble radius from the grain boundary grow into the boundary and become grain boundary bubbles. Although this assumption simplifies modeling, it violates the well-established notion that nucleation on grain boundaries is considered heterogeneous and is fixed by a density of nucleation sites and activation energies that differ from their bulk counterpart. Evans [102] later proposed that the vacancy gradient near grain boundaries drives bubble migration in the bulk toward boundaries.

\subsection{Growth and interconnection of grain boundary bubbles}

Evolution of grain boundary bubbles involves growth of individual bubbles, bubble coalescence and percolation. These mechanisms were assumed early on in modeling the role of grain boundaries in FGR [95]. The pertinent models, however, were refined later by improving the microstructure representation and the kinetics [19,70,71,103,104]. White [19] considered coalescence through bubble growth resulting in intersection and merging of bubbles through a geometrical reasoning. Considering an area surrounding each bubble of circular projection into which no other bubble can grow without resulting in coalescence, the coalescence rate is proportional to the increase rate of the bubble projected area on the grain boundary and the square of the bubble number density. White's coalescence model was further developed in Ref. [100], introducing the conservation of the total volume of the interacting bubbles. White [19] also modeled the morphological relaxation of coalesced bubbles from the bi-lobed shape resulting from coalescence back to the (energetically favored) circular projection. In addition to growth, grain boundary bubble motion was considered as a contributing factor to bubble coalescence [70]. The bubble mobility required to understand this effect was modeled by Veshchunov and Shestak [105], though for intragranular bubbles. In this model, the authors considered bubble motion by surface diffusion, bulk diffusion and evaporation condensation, and it was found that the bubble mobility by volume diffusion can be strongly enhanced under irradiation where high densities of point defects are available.

The equilibrium bubble morphology affects the rate at which grain boundary bubbles interlink, and therefore the rate of FGR to the edge network [106]. Grain boundary bubbles assume a lenticular shape where the contact angles are determined by the balance of interfacial energies between the gas and the two grains, and between the grains themselves. Since interfacial energies depend on the orientations of the solid lattice, the grain-grain interfacial energy depends on the misorientation between adjacent grains, and the grain-gas interface may also depend on the orientation of the adjacent grain lattice. Surface adsorption at the grain-bubble interface and accumulation of fission products on the grain

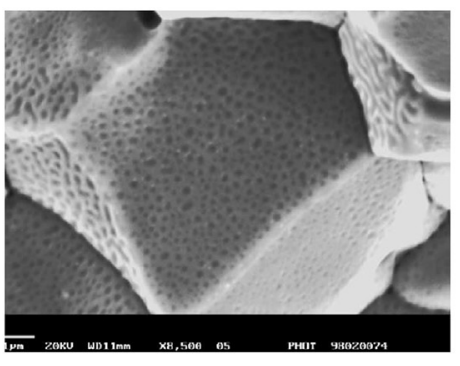

(a)

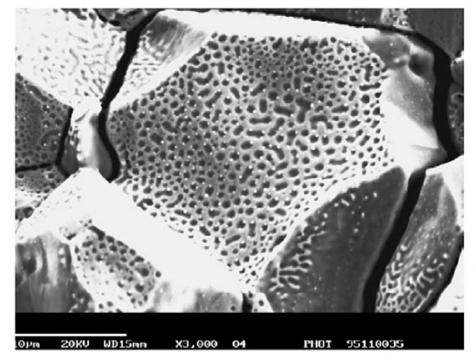

(b)

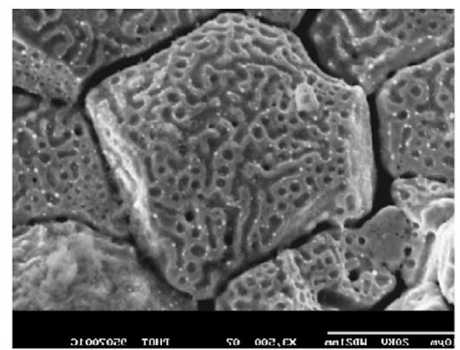

(c)

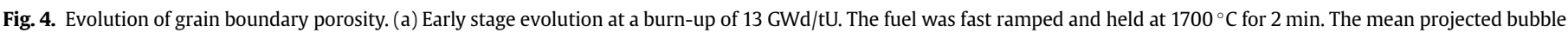

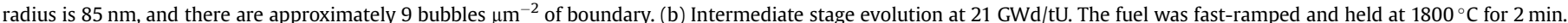

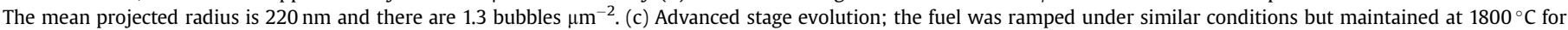

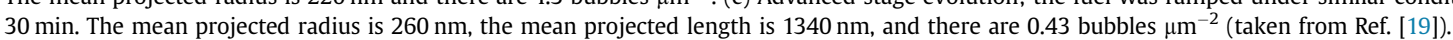


boundaries may also affect the interfacial energies. It has been observed experimentally that in $\mathrm{UO}_{2}$, the contact angle ranges from $40^{\circ}$ to $80^{\circ}$ [107].

\subsection{Modeling and simulation of grain boundary bubbles}

In spite of the fact that many models tried to incorporate grain boundary bubbles as part of representation of the microstructure, some recent models still simplified the role of grain boundaries as a diffusion path of fission gases to the grain edge tunnels or open pores $[108,109]$. The resulting models consist of a conventional diffusion equation for intragranular fission gas, with a time-varying boundary condition for the concentration along the grain boundary. The boundary values, in turn, are treated as solutions of yet another boundary diffusion equation that takes fission gas atoms ultimately to the grain edge pores, where they are considered released to the grain edge network. The second diffusion equation does not explicitly consider the mechanism of transport along the grain boundary, instead encapsulating it in the diffusion coefficient.

As an overall observation, the majority of existing FGR and swelling models recognize the importance of microstructure representation, especially the role of grain boundaries. As mentioned earlier, this role is threefold; grain boundaries act as saturable fission gas sinks, they provide a diffusion path for fission gases, although as mentioned this range is considered small, and they contribute to fission gas swelling and release by the nucleation and evolution of fission gas bubbles. In addition, grain boundary segregation properties, diffusivities and bubble behavior are anisotropic, varying with the misorientation between the adjoining grains and grain boundary inclination.

Accurately predicting the nucleation of grain boundary bubbles requires understanding the thermodynamics and kinetics of gas atom and grain boundary interactions. For example, the segregation potential for fission gases is required to be computed for various grain boundary types; see Andersson et al. [52] for a related recent study. Next comes the question of nucleation or, in general, the appearance of fission gas bubbles on the grain boundaries regardless of the nucleation site. Grain boundary energies vary, resulting in a variable density of nucleation sites and nucleation barriers. Atomistic studies can be of critical importance in revealing these characteristics and in understanding their variability; for example in Millett et al. a random walk particle algorithm was used to quantify the impact of grain boundary segregation energy and diffusivity on grain boundary bubble nucleation [110]. In addition to the fission gas atom inventory along grain boundaries, the fission gas content in the neighboring grains also impacts the nucleation process. In this sense, grain boundary nucleation does not necessarily conform to the known nucleation models. The impact of cascades on grain boundary nucleation is also expected to be a factor. Because of capillary and stress effects, and the possible grain boundary motion, fission gas nuclei might also appear in the matrix but end on nearby grain boundaries. A similar idea was pointed out by White [19].

Grain boundary bubble evolution is the next important step. As earlier models discussed, this evolution involves growth of individual bubbles and bubble coalescence by growth and movement along the boundary. Bubble growth has been so far considered in the sense of growth of a single effective (mean) bubble, and often the so-called mechanical equilibrium condition has been assumed. This condition states that the bubble pressure plus the imposed hydrostatic stress on the material balance out the surface tension of the bubble. Bubbles not satisfying this condition are called nonequilibrium bubbles, and the more general non-equilibrium formulation has been considered in some models [71,100]. The use of the three mechanical variables (pressure, hydrostatic stress, and surface tension times the curvature) to study mechanical equilibrium of bubbles is nothing but an application of the YoungLaplace equation [111] for gas bubbles in fluids; it simply states that the pressure difference across a bubble surface is balanced by the surface tension. In solids, however, the gas pressure and the surface tension provide traction components for the corresponding stress problem. When a hydrostatic stress is present it provides an additional component by virtue of the superposition of the elastic solution [100]. The stress state at the surface, however, is not simply the net normal force density acting on the surface, which is nothing but the traction boundary condition. A stress solution is thus required to fix the stress state at the surface. On the other hand, the accumulation of gas atoms into bubbles should be considered within the framework of chemical equilibrium, or non-equilibrium of bubbles with gas atoms and vacancies and interstitials. It is the chemical potentials of defects that must then be considered in sorting out the conditions of the bubbles and their stationarity of growth as a function of the local elasto-chemical state of the defects. A consequence of these considerations is the need to investigate grain boundary bubbles simultaneously with the evolution of the entire system. However, multiscale modeling that is needed to accomplish this task remains a challenge even in simple metallic systems [112]. In irradiated nuclear fuel, non-stoichiometry, grain restructuring, temperature gradients, and chemical heterogeneity make realistic modeling of FGR a formidable challenge.

Irradiation studies have shown that the morphology of grain boundary bubbles is important [19]. However effective medium models cannot account for morphology with a high level of confidence [104]. Emerging models such as phase field models can take the grain/grain boundary and bubble morphology into consideration. Phase field models of the coevolution of fission gas bubbles and grain structure have been developed [113-116], and are being used to inform the development of improved FGR models. A significant benefit of the phase field approach is that it naturally captures bubble coalescence and percolation. In fact, it is not necessary to distinguish intragranular, intergranular, and grain edge bubbles once the local thermodynamics and kinetic quantities account for the differences between bulk, grain boundary, and grain edge behavior. Accurately capturing the stochastic nature of nucleation requires the addition of stochastic terms to the phase field approach, but various nucleation approaches have been presented in the literature [117-119]. In Ref. [106], the phase field method was employed to show that the impact of the grain boundary energy on the contact angle of the lenticular bubble shape directly impacts the bubble percolation for a specific grain face. This relationship between energy and fractional coverage explains why experiments have found that neighboring grain faces can have drastically different bubble percolation, as shown in Fig. 5.

\subsection{Needs and recommendations}

While much has been learned about the evolution of grain face bubbles and their impact on FGR, there are still open questions that need to be answered.

The first open question regarding stage two of FGR is: do the majority of grain face bubbles nucleate on grain boundaries or do they nucleate in the bulk before making contact with the grain boundary? The majority of FGR models currently ignore nucleation, and some of those that include it assume that all bubbles nucleate within the bulk. Experimental observations would have the largest impact to answer this question, but experimental observation of bubble nucleation during reactor operation would be very difficult if not impossible. An alternative approach could be to employ Xe ion implantation in situ in a TEM to observe bubble nucleation at or 

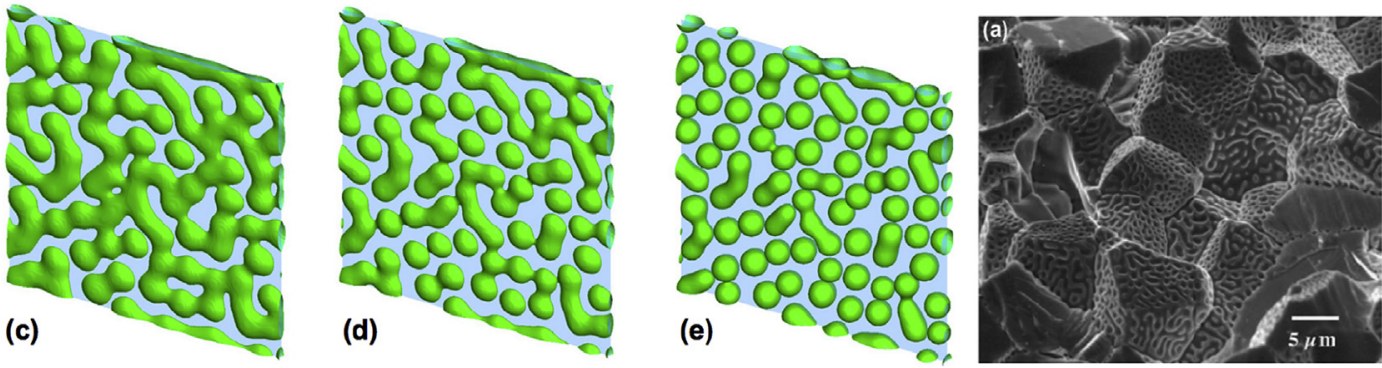

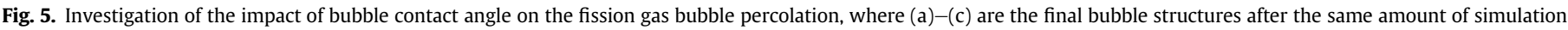

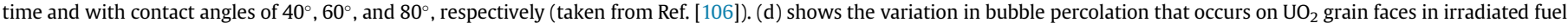
annealed for $5 \mathrm{~h}$ at $1400^{\circ} \mathrm{C}$ (taken from Ref. [120]).

near grain boundaries. The phase field method requires a separate nucleation model to capture nucleation and therefore may not be appropriate to investigate where grain face bubbles nucleate. Monte Carlo approaches could be used to effectively investigate the nucleation behavior.

The second open question is: how does grain boundary character impact the nucleation and percolation of grain face bubbles? Initial simulations have demonstrated that differences in behavior due to grain boundary character could have a significant impact on both nucleation and bubble percolation. However, these findings have not been validated with experimental data and additional simulations are needed to provide more detail on the impact of anisotropy. Careful post irradiation examination on $\mathrm{UO}_{2}$ fuel with increasing amounts of burnup employing SEM and electron backscatter diffraction could be used to characterize bubble structures on grain boundaries with different misorientation angles. Additional simulations, such as phase field simulations, are needed to determine the impact of grain boundary character on overall fission gas release, to determine if it should be considered in engineering scale FGR models.

The final open question for stage two is: what happens to percolated grain face bubble networks once the gas atoms escape? The remaining pores may shrink and disappear, depending on the conditions and rate at which new gas atoms enter them. This behavior could be investigated using both experiments and mesoscale simulation. Post irradiation annealing could be used to determine the rate at which bubbles shrink once their gas is released. However, gas generation is needed to determine the behavior in reactor. Phase field simulations that consider vacancy and gas atom concentrations separately could provide a means of answering this question.

\section{Stage 3: gaseous fission product release}

The third and last stage of thermal FGR in oxide fuel is the development of gas bubbles along grain boundary triple junctions (grain edges), which eventually form a continuous network of porosity extending to the fuel outer surface and providing a route for gas venting to the fuel rod free volume [20,21,121-129]. This interpretation is supported by experimental observations of irradiated fuel, showing populations of lenticular gas bubbles occupying the faces of the grains and long tunnel-like interconnected pores along the grain edges, often open to the exterior of the fuel sample (Fig. 6) [20,21,122,130,131].

\subsection{Experimental evidence of grain edge bubbles}

The behavior of grain-edge bubbles is important both because they eventually interlink to provide a path for fission gas atoms to escape from the fuel and because they account for a significant portion of fuel gaseous swelling. Experiments showed that at low burn-up the contributions of grain-face and grain-edge porosities to the overall swelling are about equal, but as irradiation proceeds, the contribution due to grain-edge tunnels exceeds that due to grain-face bubbles [20,21,122]. The formation and maintenance of the grain-edge tunnel network is itself dependent upon gas transfer from lenticular gas bubbles at the grain faces to grain edges $[20,122,124,125]$. Most of the fission gas atoms trapped in grain-face bubbles are not released to the grain edges until extensive coalescence occurs. Before this happens, however, those bubbles situated near a grain edge will eventually grow into contact with it. In this event, the bubble will move by a surface diffusion mechanism to take up an energetically more favorable cigar shape situated along
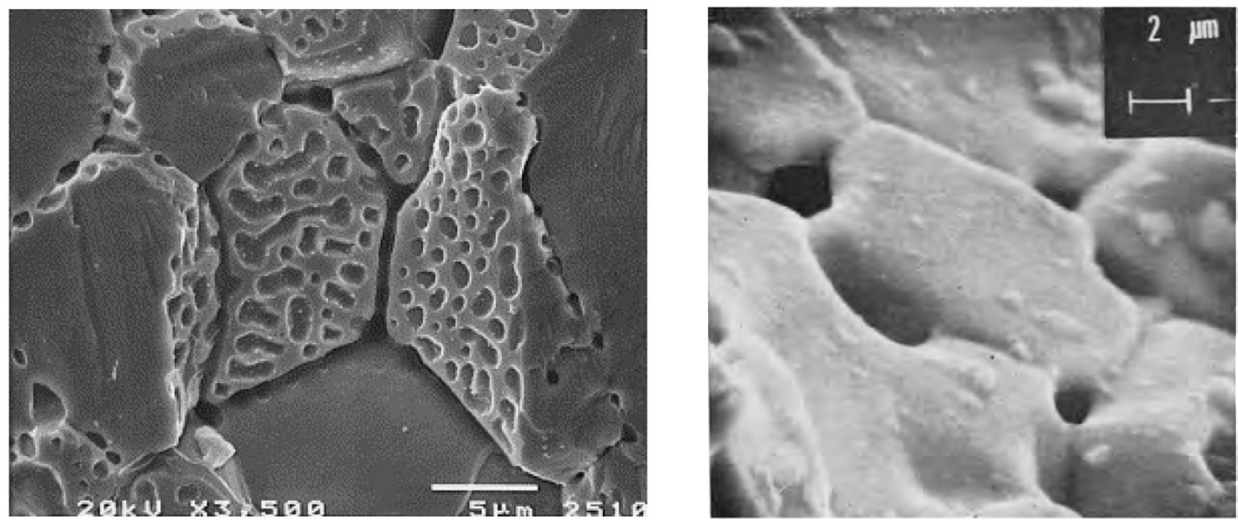

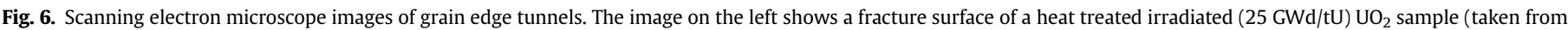
Ref. [127]). The image on the right shows the external fuel surface with a 'quilting' effect caused by the emergence of grain edge tunnels at the surface (taken from Ref. [122]). 
the grain edge. This cigar shape is essentially cylindrical with a center axis along the grain edge, in contrast with a lenticular grain face bubble that has a circular cross-section on the grain face. In this process, in order to restore mechanical equilibrium with the surface tension force, the volume of the grain-edge bubble increases by absorbing vacancies created on the grain faces. The resulting pore extends along the grain edge to a length considerably greater than the original bubble diameter [125]. Indeed, at low swelling values, grain edge tunnels (formed by the coalescence of multiple cigar shaped grain edge bubbles) are inclined to collapse under the effect of surface tension, which provides a driving force for a flow of vacancies from the tunnels to the grain faces [122]. The process of collapse and reformation may be repeated again and again, with the tunnel volume growing as a result of each cycle. However, when the volume swelling caused by the tunnels is sufficiently large, the tunnel networks become stable and remain open $[20,21,122,123,125,132]$. Different values have been reported for the critical grain-edge swelling at the formation of extensive interlinked porosity, which generally range from about 5 to $10 \%$ [20,121-123]. In this condition, fission gas reaching open tunnels is free to escape from the fuel leading to FGR.

\subsection{Modeling and simulation of the third stage of gas release}

In fission gas behavior models, the third stage of FGR may be modeled explicitly, or alternatively, incorporated within an effective description of the overall gas behavior at grain boundaries. The latter, simpler approach typically involves a saturation limit for the global gas storing capacity of grain boundaries, the excess gas being considered as instantaneously released to the fuel exterior (e.g., $[25,70,99,100]$. The more detailed modeling of FGR and grain boundary gaseous swelling calls for an explicit distinction between gas behavior at grain faces and at grain edges. This implies that transfer of gas atoms and vacancies between grain faces and grain edges as well as FGR from the grain edges are described.

Beeré and Reynolds [121] investigated the free energy of a system of interlinked grain-edge pores as a function of its dimensions and gas content, assuming a simplified geometry composed of connected spheres and frusta. Their model predicted that gas release may occur only after attainment of a critical swelling for the establishment of interlinked tunnels, and release occurred by repeated venting and re-sintering of the tunnels. Turnbull and Tucker [122] developed a model to describe the kinetics of grainedge swelling beyond the threshold value for extensive tunnel interlinkage and FGR. The diffusive flux of vacancies between the grain faces and the grain-edge tunnels is modeled considering two components, i.e., the swelling flux associated with the release of fission gas from grain-face bubbles and the sintering flux driven by the surface tension in the tunnel walls. Within this model, they adopted a simplified geometrical representation considering tetrakaidecahedral grains with circular cylindrical tunnels at grain edges representing the interlinked porosity. A more accurate description of the geometry of grain-edge porosity was proposed by Tucker and Turnbull [123], who developed a model for interconnected grain edge porosity based on a system of interlinked catenoid-like surfaces ("catenoid model"). The solid is considered as composed of identical tetrakaidecahedral grains. Based on geometric considerations, they determined the curvature of the tunnels and the fraction of the grain area forming tunnel surface as a function of the fractional volume swelling. An implication is the existence of the critical swelling value, below which the tunnel structure is unstable and tends to collapse. Given the complexity of the catenoid model, which makes it unfit for coupling with vacancy-diffusion based swelling calculations (such as those from Turnbull and Tucker [122]), Tucker [132] developed a simpler model in which the tunnel surfaces are represented as segments of a toroid ("toroid model"). The toroid model is consistent with the catenoid model above the critical swelling and has the added advantage of also describing the porosity in the lower swelling range which, although inherently unstable, is constantly reforming after collapse. Koo et al. [103] developed a model for FGR and swelling in $\mathrm{UO}_{2}$, explicitly considering the gas behavior at grain edges. Using the assumptions that a $\mathrm{UO}_{2}$ grain surface consists of 14 identical circular faces and that a grain-edge bubble can be represented by a triangulated tube around the circumference of three circular grain faces, the model calculates gas bubble swelling at grain edges and FGR. Thermal FGR is proportional to the arrival rate of gas at the grain edges and the fraction of grain-edge bubbles linked to the fuel surface. The latter is a representation of the formation of release tunnels and is considered proportional to the grain-edge swelling.

There has been recent work considering explicit tunnel interlinkage through network percolation simulations by Millett et al. [115,133], and Sabogal-Suárez et al. [134], and examples are shown in Fig. 7. These simulations consider a network of interconnected grain edges each of which may be in either an open or closed state. When an interconnected chain of edges reaches a free surface (pellet surface or a crack) the gas contained on those edges is considered to vent. Millett [133] was the first to apply this percolation approach to FGR, considering 2D circular and 3D cylindrical

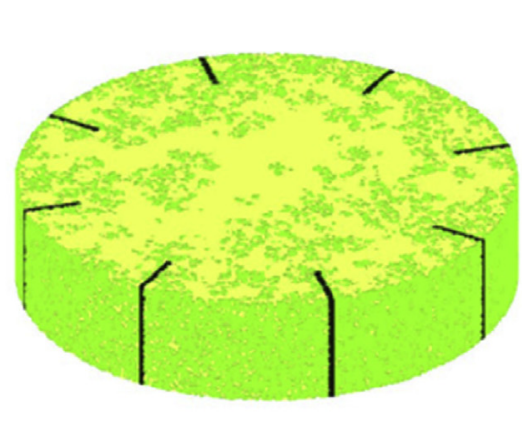

(a)

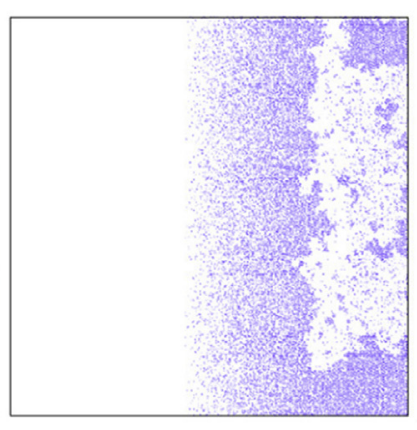

(b)

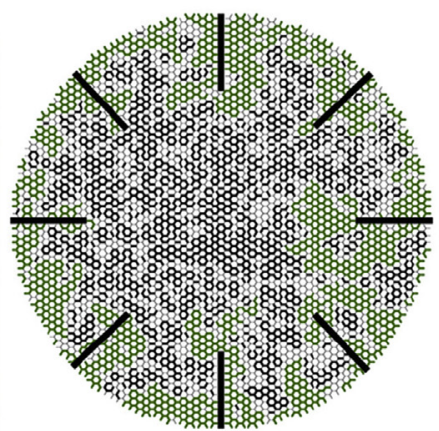

(c)

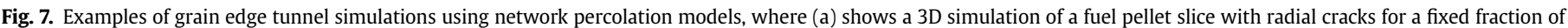

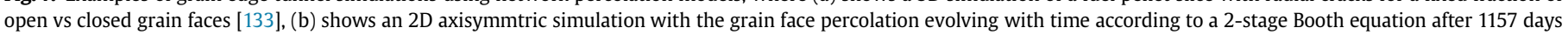
[115], and (c) shows a 2D slice of a pellet with cracks and a crystallographically consistent grain boundary network [134]. 
geometries. Radial cracks were included, but only significantly impacted the FGR when a temperature gradient was included. Millett et al. [115] enhanced the initial model using axisymmetric geometries and a time dependent model where gas accumulates on the grain edges as a result of a 2-stage Booth equation $[23,24,94]$ in the adjacent grain. Once the grain edge saturation is reached, which depends on the contact angle, the edge is marked open. When the chain of interconnected porosity vents, all of the connected edges are marked closed, representing the annealing of the tunnel. These simulations show that the venting primarily occurs along the hot, inner region towards the top and bottom of the pellet, and that the grains in the cooler outer region never reach the saturated criteria. Their simulations also show that the requirement for percolation delays the release of gas on the grain edges, which allows greater gas resolution to occur, reducing the overall FGR. When the gas resolution rate is set to zero, the percolation condition predictions are similar to those of the 2-stage Booth model; as the gas resolution rate increases to $\sim 10^{-5} \mathrm{~s}^{-1}$, the onset of FGR is delayed, and the total release fraction drops by $25-40 \%$.

Sabogal-Suárez et al. [134] considered a cylindrically symmetric model using a crystallographically consistent grain boundary network, and included the effects of radial cracks. Their simulations are static, in which the probability of a grain edge being open is a function of the misorientation angle and the radial position, which represents the effects of a radial temperature profiles on grain face saturation. To obtain a crystallographically consistent network, they assigned each grain a random orientation and calculated the edge misorientation angles from this information, as compared to Millet [133] whose misorientation angles were random. SabogalSuárez et al. showed that crystallographic consistency results in a texture with more clustering of open edges, which limits the extent of interconnected chains and thus the fraction of vented gas at each venting event. They also demonstrate that the radial cracks help penetrate the cooler outer regions in order for percolation to occur faster, however they acknowledge that in a model including axial displacement along the hot centerline, the impact of radial cracks may be diminished.

White [19] explicitly considered the evolution of grain boundary bubble morphology and modeled FGR through venting of elongated bubbles to the grain edges, with a phenomenological treatment of bubble-length/grain-edge intersection probability.

\subsection{Needs and recommendations}

Introducing the explicit description of the third stage of FGR as part of a detailed fission gas behavior model calls for suitably describing the physical mechanisms that characterize the gas behavior at grain edges, however there are still open questions regarding these mechanisms.

The first open question in the third stage of FGR is: are some grain edges more likely to form tunnels and if so, does this anisotropy significantly impact FGR? Post irradiation examination of $\mathrm{UO}_{2}$ samples with increasing burnup, using SEM and EBSD, could determine if certain grain edges (characterized by the orientations of the three grains that meet to create the grain edge) are more likely to form tunnels. 3D phase field simulations could be used to quantify the impact of grain edge anisotropy on the overall FGR, though they would be very expensive calculations. 3D network percolation algorithms that represent each triple junction could be a more computationally efficient alternative.

The second open question is: how is gas transferred from grain faces to grain edges? Answering this question using experiments would be extremely difficult, as it is difficult to track the migration of gas atoms through the bubble networks. Modeling of gas transfer from grain faces to edges may be based on the mechanism put forward by Turnbull [20], whereby bubbles nucleated on the grain faces grow until they coalesce with the porosity along the grain edges, where they discharge their gas. This would be captured using a geometrical reasoning. The model may involve a saturation value for the coverage of grain faces by bubbles, for which gas is transferred to the grain edges after attainment of the saturation coverage $[19,100,103]$. A more detailed approach may be based on 3D network percolation algorithms or 3D phase field modeling.

The final open question for stage three is: how do grain edge bubbles evolve over time? Investigating the evolution of bubbles with experiments could possibly be answered using postirradiation annealing in situ with a non-destructive 3D characterization approach such as high energy X-ray diffraction microscopy. In the simplest modeling approach, this may be obtained by representing grain-edge bubbles as triangulated tubes in mechanical equilibrium with the surrounding material, so that bubble volume and swelling can be calculated based solely on the gas atom flux from the grain faces and an equation of state [103]. For a more detailed physical description, the direct modeling of vacancy diffusion between the grain-face bubbles and the grain-edge tunnels during coalescence may be explored. The grain-edge bubble volume and swelling would then be determined by the flux of gas atoms and vacancies to the grain-edge porosity and the sintering vacancy flux acting in the opposite direction. This could be pursued, for instance, by taking up the approach of Turnbull and Tucker [122] and evolving it to consider a more accurate description of the geometry of grain-edge porosity [132].

\section{Non-diffusional mechanisms}

As discussed in the previous sections, the primary mechanism for FGR is the diffusion of gas atoms through the $\mathrm{UO}_{2}$ matrix, the percolation of grain face bubbles, and the release of gas to free surfaces through grain edge tunnels. However, it has been clearly observed that there are some mechanisms for FGR that are not caused by diffusion. One such mechanism is release due to direct recoils from fission events or by knockouts. Another occurs during rapid power transients, resulting in a jump in the FGR as shown in Fig. 7 [101,135-139]. This phenomenon is typically called "burst release." In single crystals, the effect appears to be caused by a knockout mechanism [140]. The effect is more pronounced in polycrystalline fuel, and appears to be caused by microcracking along grain boundaries induced by rapid thermal stresses and gas bubble pressure, also shown in Fig. 8.

\subsection{Release due to recoil and knockouts}

Early investigations of the FGR in $\mathrm{UO}_{2}$ single crystal samples below $1000{ }^{\circ} \mathrm{C}$ showed the presence of very short-lived fission products with temperature independent release rates. Based on the relative immobility of fission gases at these temperatures, it was concluded that the observed releases should correspond to direct recoils from fission events or knockouts, when the primary fragment interacts with other fission gases in the lattice. Only fission products formed at the external surface of the $\mathrm{UO}_{2}$ pellets can escape by these mechanisms. These processes were studied by Olander [1], Wise [142], and Lewis [143] to understand their importance on releases in fuel operating at low powers. Based on the mathematical treatment developed by Lewis [143] applied to the analysis of several experiments [144-146], it was demonstrated that recoil plays an important role on modelling gas releases from low-powered fuel and it is the dominant gas release mechanism for fuel debris deposited on in-core surfaces. 

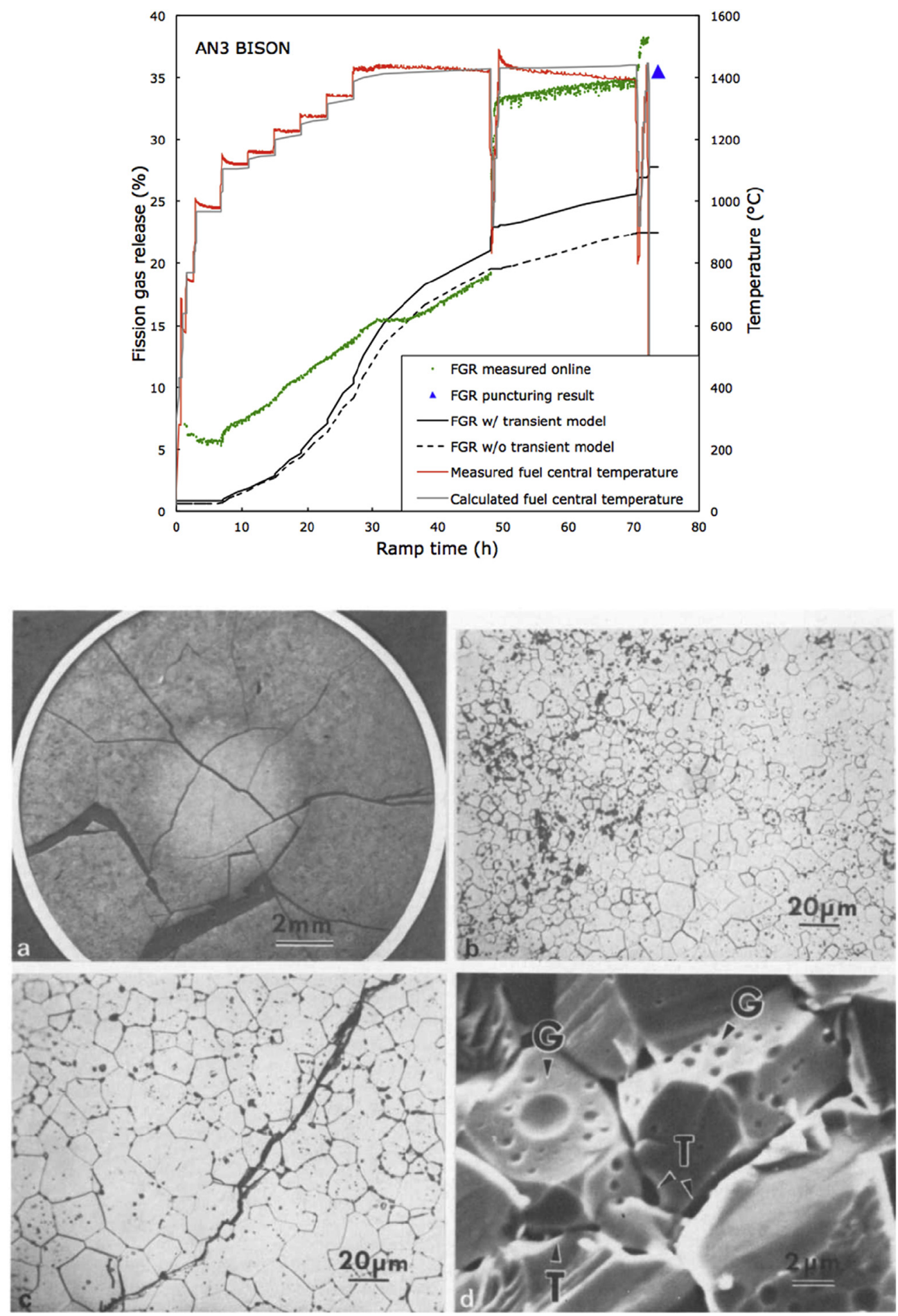

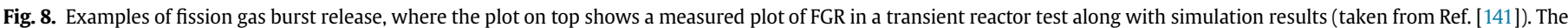

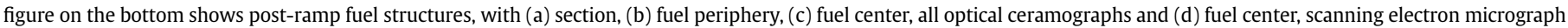
showing intergranular fission gas bubbles $(G)$ and grain edge tunnels (T) (taken from Ref. [137]).

\subsection{Experimental evidence of burst release}

During post-irradiation annealing, both rapid increases and decreases in temperature have resulted in fission gas burst release. However, burst release primarily occurred within a specific temperature range, with maximum release at about $1500^{\circ} \mathrm{C}$ $[69,147,148]$, though it depends on burn-up. In transient irradiations, the kinetics of FGR is determined from measurements of the pressure within the fuel rod. Notley and MacEwan [135] and Carroll et al. [136] ascribed these sudden jumps in FGR during transients to micro-cracking along grain boundaries. Transient-tested $\mathrm{UO}_{2}$ fuel rods exhibit grain face separations [101,137,138,149] observed using microscopy, and it was postulated that these cracks released all fission gas stored on the cracked grain boundaries. This postulated mechanism explains the rapid kinetics of burst release and why some grain boundaries release their gas but others do not. Cayet 
[27] suggests a different mechanism; he ascribed the rapid change in pressure during a power drop to the opening of the gap, allowing gas released previously but unable to reach the plenum to transport to the plenum and be detected by the pressure transducer. However, this mechanism does not fully describe the behavior, as burst release has been observed in transient experiments where pelletcladding interaction was absent $[69,147,148]$.

\subsection{Modeling and simulation of burst release}

Attempts to model fission gas burst release have been focused on the engineering scale, to provide a means to represent this phenomenon in fuel performance codes. The one exception from this is the work from Chakraborty et al. [150] in which finite element simulations were used to determine the bubble pressure required for grain boundary separation. For fuel performance codes, various models have been developed to describe the increase in FGR during transients [151-155]. Some approaches [151,152,154] add a contribution of gas release from grain boundaries due to micro-cracking when specific empirical conditions regarding the power occur. In addition, a burn-up dependent temperature threshold is used in some of the models [152,154]. The model from Bernard et al. [153] reduces the gas concentration at grain boundaries after the beginning of a transient according to an exponential function. The model of Hering [151] includes a restoration of the gas storing capacity of cracked grain to account for crack healing. Pastore et al. [155] extend an existing diffusion-controlled FGR model by reducing the grain-face gas inventory and storing capacity as the local temperature varies during transients. An empirical temperature-dependent function is developed to represent the micro-cracking mechanism. Compared to previous ones, this model allows for continuous kinetics of FGR and preserves the physical coupling between FGR and gaseous swelling. This model was further improved by introducing an explicit dependence of transient release on fuel burn-up, and applied in multiple fuel performance codes [141].

\subsection{Needs and recommendations}

Although the process of burst release is still a subject of active discussion, the theory involving grain-boundary separation due to micro-cracking is acknowledged by several authors and finds support in the available experimental evidence. However, a definitive answer is still needed for the primary question: what is the mechanisms that drives burst release? One possible experimental approach to answer this question would be to characterize fuel microstructures directly after burst before they have had a chance to heal. 3-D characterization that determines grain orientations, such as high energy x-ray diffraction microscopy, would be especially valuable to determine which grain boundaries are most likely to separate. Atomistic simulation could then be used to quantify the properties of these grain boundaries. Atomistic and mesoscale simulation approaches could be used to model the grain boundary separation and determine quantitative thresholds for when separation occurs.

All new insights into burst release should then be used to develop mechanistic models for fuel performance codes to describe burst release. All current burst release models use empirical thresholds for when grain separation occurs, but for a fuel performance code to be truly predictive, these models need to physically describe the primary mechanisms.

\section{Conclusions}

The production and release of fission gases in $\mathrm{UO}_{2}$ reactor fuel has a large impact on the fuel performance, causing swelling and the degradation of properties such as thermal conductivity and fracture toughness, and reducing the gap conductivity and increasing the gap pressure. Due to its importance, fission gas behavior and release have been studied experimentally and modeled for many years. These studies have found that the majority of FGR results from three stages: in stage one gas atoms are produced and migrate through the bulk; in stage two grain face bubbles nucleate, grow, and interconnect until they contact grain edges; in stage three gas transports through interconnected grain edge tunnels until it reaches a free surface and is released. In addition to these mechanisms that are based on gas atom diffusion, some gas release occurs due to knockout and recoil and burst release. In this work, experimental findings from the literature for each stage of gas release and for the non-diffusional mechanisms have been reviewed. A summary has also been provided of the modeling and simulation efforts that have been carried out to predict fission gas behavior.

In addition to the review of past work on fission gas, needs and recommendations have been provided that focus on open questions that still need to be answered. For the convenience of the reader, these questions are restated here, and suggestions on how these questions could be answered can be found in their corresponding sections.

Stage 1 of gas release:

- How does non-stoichiometry impact the intrinsic diffusion of $\mathrm{Xe}$ in $\mathrm{UO}_{2}$ ?

- What defects drive the acceleration of diffusion due to radiation at temperatures between 1300 and $1600 \mathrm{~K}$ ?

- What drives the formation of a multimodal intragranular bubble size distribution at higher temperature and burnup?

- What is the relative importance of homogeneous and heterogeneous resolution of gas atoms from intragranular bubbles?

Stage 2 of gas release

- Do the majority of grain face bubbles nucleate on grain boundaries or do they nucleate in the bulk before making contact with the grain boundary?

- How does grain boundary character impact the nucleation and percolation of grain face bubbles?

- What happens to percolated grain face bubble networks once the gas atoms escape?

Stage 3 of gas release

- Are some grain edges more likely to form tunnels and if so, does this anisotropy significantly impact FGR?

- How is gas transferred from grain faces to grain edges?

- How do grain edge bubbles evolve over time?

Non-diffusional mechanisms

- What is the mechanism that drives burst release?

The mechanistic understanding of fission gas behavior surveyed in this work has the potential to revolutionize our ability to predict fission gas behavior during reactor operation and to design fuels that have improved fission gas retention, though more work needs to be done. In addition, the combined efforts of experiments and modeling applied to understand FGR can serve as a model of how this combined approach could be applied to understand the unit mechanisms behind other critical behaviors in reactor materials.

\section{Acknowledgments}

The authors would like to acknowledge the OECD Nuclear Energy Agency Working Party on Multi-Scale Modelling of Fuels and Structural Materials for Nuclear Systems (WPMM) for fostering this 
collaboration. MRT and RD were supported by the US DOE Nuclear Energy Advanced Modeling and Simulation program. SRP was supported by DOE NEUP Award (DENE0000731).

\section{References}

[1] D.R. Olander, Fundamental Aspects of Nuclear Reactor Fuel Elements, Dept. of Nuclear Engineering, California Univ., Berkeley (USA), 1976.

[2] D.G. Cacuci, Handbook of Nuclear Engineering, vol. 1, Nuclear Engineering Fundamentals, Springer Science \& Business Media, 2010.

[3] G. Pastore, L.P. Swiler, J.D. Hales, S.R. Novascone, D.M. Perez, B.W. Spencer, L. Luzzi, P. Van Uffelen, R.L. Williamson, Uncertainty and sensitivity analysis of fission gas behavior in engineering-scale fuel modeling, J. Nucl. Mater. 456 (2015) 398-408, https://doi.org/10.1016/j.jnucmat.2014.09.077.

[4] W. Li, G. Liu, H. Wang, H. Zhang, J. Luan, A. Ullah, Topological correlations of grain faces in polycrystal with experimental verification, EPL Europhys. Lett. 104 (2013) 56006, https://doi.org/10.1209/0295-5075/104/56006.

[5] H. Bailly, D. Ménessier, C. Prunier, Le combustible nucléaire des réacteurs à eau sous pression et des réacteurs à neutrons rapides: conception et comportement, Eyrolles, 1996.

[6] S. Katcoff, Fission-product Yields from Neutron-induced Fission vol. 18, 1960. Nucleon. US Ceased Publ.

[7] F. Lisman, R. Abernathey, W. Maeck, J. Rein, Fission yields of over 40 stable and long-lived fission products for thermal neutron fissioned $233 \mathrm{U}, 235 \mathrm{U}$ $239 \mathrm{Pu}$, and $241 \mathrm{Pu}$ and fast reactor fissioned $235 \mathrm{U}$ and $239 \mathrm{Pu}, \mathrm{Nucl}$. Sci. Eng. 42 (1970) 191-214.

[8] Nuclear Energy Agency, (n.d.). http://www.oecd-nea.org/dbforms/data/eva/ evatapes/jeff_32/.

[9] M.B. Chadwick, M. Herman, P. Obložinský, M.E. Dunn, Y. Danon, A.C. Kahler, D.L. Smith, B. Pritychenko, G. Arbanas, R. Arcilla, R. Brewer, D.A. Brown, R. Capote, A.D. Carlson, Y.S. Cho, H. Derrien, K. Guber, G.M. Hale, S. Hoblit, S. Holloway, T.D. Johnson, T. Kawano, B.C. Kiedrowski, H. Kim, S. Kunieda, N.M. Larson, L. Leal, J.P. Lestone, R.C. Little, E.A. McCutchan, R.E. MacFarlane, M. MacInnes, C.M. Mattoon, R.D. McKnight, S.F. Mughabghab, G.P.A. Nobre, G. Palmiotti, A. Palumbo, M.T. Pigni, V.G. Pronyaev, R.O. Sayer, A.A. Sonzogni, N.C. Summers, P. Talou, I.J. Thompson, A. Trkov, R.L. Vogt, S.C. van der Marck, A. Wallner, M.C. White, D. Wiarda, P.G. Young, ENDF/B-VII.1 nuclear data for science and technology: cross sections, covariances, fission product yields and decay data, Nucl. Data Sheets 112 (2011) 2887-2996, https://doi.org/ 10.1016/j.nds.2011.11.002.

[10] B. Michel, C. Nonon, J. Sercombe, F. Michel, V. Marelle, Simulation of pelletcladding interaction with the pleiades fuel performance software environment, Nucl. Technol. 182 (2013) 124-137.

[11] M. Veshchunov, A. Boldyrev, A. Kuznetsov, V. Ozrin, M. Seryi, V. Shestak, V. Tarasov, G. Norman, A.Y. Kuksin, V. Pisarev, Development of the advanced mechanistic fuel performance and safety code using the multi-scale approach, Nucl. Eng. Des. 295 (2015) 116-126.

[12] R.L. Williamson, J.D. Hales, S.R. Novascone, M.R. Tonks, D.R. Gaston, C.J. Permann, D. Andrs, R.C. Martineau, Multidimensional multiphysics simulation of nuclear fuel behavior, J. Nucl. Mater. 423 (2012) 149-163, https://doi.org/10.1016/j.jnucmat.2012.01.012.

[13] V. Marelle, P. Goldbronn, S. Bernaud, E. Castelier, J. Julien, K. Nkonga, L. Noirot, I. Ramière, New developments in ALCYONE 2.0 fuel performance code, in: Proc. Conf. Top Fuel, 2016.

[14] M.S. Veshchunov, V.I. Tarasov, An advanced model for grain face diffusion transport in irradiated UO2 fuel. Part 1: model formulation, J. Nucl. Mater. 392 (2009) 78-84, https://doi.org/10.1016/j.jnucmat.2009.03.055.

[15] R. Sanchez, I. Zmijarevi, M. Coste-Delclaux, E. Masiello, S. Santandrea, E. Martinolli, L. Villate, N. Schwartz, N. Guler, APOLLO2 year 2010, Nucl. Eng. Technol 42 (2010) 474-499, https://doi.org/10.5516/NET.2010.42.5.474.

[16] K. Mer-Nkonga, N. Crouzet, J. Le Pallec, B. Michel, D. Schneider, A. Targa, Coupling of fuel performance and neutronic codes for PWR, in: 11th World Congr. Comput. Mech. WCCM XI 5th Eur. Conf. Comput. Mech. ECCM V 6th Eur. Conf. Comput. Fluid Dyn. ECFD VI Barc. Spain, 2014.

[17] D.R. Gaston, C.J. Permann, J.W. Peterson, A.E. Slaughter, D. Andrš, Y. Wang, M.P. Short, D.M. Perez, M.R. Tonks, J. Ortensi, L. Zou, R.C. Martineau, Physicsbased multiscale coupling for full core nuclear reactor simulation, Ann. Nucl. Energy 84 (2015) 45-54, https://doi.org/10.1016/j.anucene.2014.09.060.

[18] R.J. White, M.O. Tucker, A new fission-gas release model, J. Nucl. Mater. 118 (1983) 1-38, https://doi.org/10.1016/0022-3115(83)90176-9.

[19] R.J. White, The development of grain-face porosity in irradiated oxide fuel, J. Nucl. Mater. 325 (2004) 61-77, https://doi.org/10.1016/ j.jnucmat.2003.10.008.

[20] J.A. Turnbull, The effect of grain size on the swelling and gas release properties of uo2 during irradiation, J. Nucl. Mater. 50 (1974) 62-68, https:// doi.org/10.1016/0022-3115(74)90061-0.

[21] J.A. Turnbull, C.A. Friskney, The relation between microstructure and the release of unstable fission products during high temperature irradiation of uranium dioxide, J. Nucl. Mater. 71 (1978) 238-248, https://doi.org/10.1016/ 0022-3115(78)90421-X.

[22] J.A. Turnbull, C.A. Friskney, J.R. Findlay, F.A. Johnson, A.J. Walter, The diffusion coefficients of gaseous and volatile species during the irradiation of uranium dioxide, J. Nucl. Mater. 107 (1982) 168-184, https://doi.org/10.1016/0022-
3115(82)90419-6.

[23] M.V. Speight, A calculation on the migration of fission gas in material exhibiting precipitation and Re-solution of gas atoms under irradiation, Nucl. Sci. Eng. 37 (1969) 180-185.

[24] A. Booth, A Method of Calculating Gas Diffusion from UO2 Fuel and its Application to the X-2-f Test, Technical Report Technical Report AECL 496 CRDC-721, Atomic Energy of Canada Limited, 1957.

[25] K. Forsberg, A.R. Massih, Fission gas release under time-varying conditions, J. Nucl. Mater. 127 (1985) 141-145, https://doi.org/10.1016/0022-3115(85) 90348-4.

[26] K. Forsberg, A.R. Massih, Diffusion theory of fission gas migration in irradiated nuclear fuel UO2, J. Nucl. Mater. 135 (1985) 140-148, https://doi.org/ 10.1016/0022-3115(85)90071-6.

[27] K. Forsberg, A.R. Massih, Kinetics of fission product gas release during grain growth, Model. Simulat. Mater. Sci. Eng. 15 (2007) 335, https://doi.org/ 10.1088/0965-0393/15/3/011.

[28] C.R.A. Catlow, Fission gas diffusion in uranium dioxide, Proc. R. Soc. Lond Math. Phys. Eng. Sci. 364 (1978) 473-497, https://doi.org/10.1098/ rspa.1978.0213.

[29] A.E. Thompson, C. Wolverton, Pathway and energetics of xenon migration in uranium dioxide, Phys. Rev. B 87 (2013) 104105, https://doi.org/10.1103/ PhysRevB.87.104105.

[30] D.A. Andersson, B.P. Uberuaga, P.V. Nerikar, C. Unal, C.R. Stanek, U and Xe transport in UO2: density functional theory calculations, Phys. Rev. B 84 (2011) 054105, https://doi.org/10.1103/PhysRevB.84.054105.

[31] X.-Y. Liu, B.P. Uberuaga, D.A. Andersson, C.R. Stanek, K.E. Sickafus, Mechanism for transient migration of xenon in UO2, Appl. Phys. Lett. 98 (2011) 151902, https://doi.org/10.1063/1.3579198.

[32] J.-P. Crocombette, Ab initio energetics of some fission products ( $\mathrm{Kr}, \mathrm{I}, \mathrm{Cs}, \mathrm{Sr}$ and $\mathrm{He}$ ) in uranium dioxide, J. Nucl. Mater. 305 (2002) 29-36, https:// doi.org/10.1016/S0022-3115(02)00907-8.

[33] M. Freyss, N. Vergnet, T. Petit, Ab initio modeling of the behavior of helium and xenon in actinide dioxide nuclear fuels, J. Nucl. Mater. 352 (2006) 144-150, https://doi.org/10.1016/j.jnucmat.2006.02.048.

[34] T. Petit, M. Freyss, P. Garcia, P. Martin, M. Ripert, J.-P. Crocombette, F. Jollet Molecular modelling of transmutation fuels and targets, J. Nucl. Mater. 320 (2003) 133-137, https://doi.org/10.1016/S0022-3115(03)00179-X.

[35] T. Petit, G. Jomard, C. Lemaignan, B. Bigot, A. Pasturel, Location of krypton atoms in uranium dioxide, J. Nucl. Mater. 275 (1999) 119-123, https:// doi.org/10.1016/S0022-3115(99)00127-0.

[36] X.-Y. Liu, B.P. Uberuaga, P. Nerikar, C.R. Stanek, K.E. Sickafus, Thermodynamics of fission products in dispersion fuel designs - first-principles modeling of defect behavior in bulk and at interfaces, Nucl. Instrum. Methods Phys. Res. Sect. B Beam Interact. Mater. At 268 (2010) 3014-3017. https://doi.org/10.1016/j.nimb.2010.05.030.

[37] A.E. Thompson, C. Wolverton, First-principles study of noble gas impurities and defects in UO\$\{ \}_\{2\}\$, Phys. Rev. B 84 (2011) 134111, https://doi.org/ 10.1103/PhysRevB.84.134111.

[38] Y. Yun, H. Kim, H. Kim, K. Park, Atomic diffusion mechanism of Xe in UO2, J. Nucl. Mater. 378 (2008) 40-44, https://doi.org/10.1016/ j.jnucmat.2008.04.013.

[39] Y. Yun, P.M. Oppeneer, H. Kim, K. Park, Defect energetics and Xe diffusion in UO2 and ThO2, Acta Mater. 57 (2009) 1655-1659, https://doi.org/10.1016/ j.actamat.2008.12.010.

[40] P.V. Nerikar, X.-Y. Liu, B.P. Uberuaga, C.R. Stanek, S.R. Phillpot, S.B. Sinnott, Thermodynamics of fission products in UO $2 \pm \mathrm{X}$, J. Phys. Condens. Matter 21 (2009) 435602, https://doi.org/10.1088/0953-8984/21/43/435602.

[41] E. Vathonne, D.A. Andersson, M. Freyss, R. Perriot, M.W.D. Cooper, C.R. Stanek, M. Bertolus, Determination of krypton diffusion coefficients in uranium dioxide using atomic scale calculations, Inorg. Chem. 56 (2017) 125-137, https://doi.org/10.1021/acs.inorgchem.6b01560.

[42] D.A. Andersson, P. Garcia, X.-Y. Liu, G. Pastore, M. Tonks, P. Millett, B. Dorado, D.R. Gaston, D. Andrs, R.L. Williamson, R.C. Martineau, B.P. Uberuaga, C.R. Stanek, Atomistic modeling of intrinsic and radiation-enhanced fission gas (Xe) diffusion in: implications for nuclear fuel performance modeling J. Nucl. Mater. 451 (2014) 225-242, https://doi.org/10.1016/ j.jnucmat.2014.03.041.

[43] R.W. Grimes, C.R.A. Catlow, The stability of fission products in uranium dioxide, Philos. Trans. R. Soc. Lond. Math. Phys. Eng. Sci. 335 (1991) 609-634, https://doi.org/10.1098/rsta.1991.0062.

[44] R.G.J. Ball, R.W. Grimes, Diffusion of Xe in UO2, J. Chem. Soc. Faraday. Trans. 86 (1990) 1257-1261.

[45] R.G.J. Ball, R.W. Grimes, A comparison of the behaviour of fission gases in UO2 $\pm \mathrm{X}$ and $\alpha-\mathrm{U} 308-\mathrm{z}$, J. Nucl. Mater. 188 (1992) 216-221, https://doi.org/ 10.1016/0022-3115(92)90474-Y.

[46] K. Govers, S.E. Lemehov, M. Verwerft, On the solution and migration of single $\mathrm{Xe}$ atoms in uranium dioxide - an interatomic potentials study, J. Nucl. Mater. 405 (2010) 252-260, https://doi.org/10.1016/j.jnucmat.2010.08.013.

[47] S.T. Murphy, A. Chartier, L. Van Brutzel, J.-P. Crocombette, Free energy of Xe incorporation at point defects and in nanovoids and bubbles in UO2, Phys. Rev. B 85 (2012) 144102, https://doi.org/10.1103/PhysRevB.85.144102.

[48] S. Nicoll, H. Matzke, C.R.A. Catlow, A computational study of the effect of Xe concentration on the behaviour of single Xe atoms in UO2, J. Nucl. Mater. 226 (1995) 51-57, https://doi.org/10.1016/0022-3115(95)00131-X.

[49] M.W.D. Cooper, C.R. Stanek, J.A. Turnbull, B.P. Uberuaga, D.A. Andersson, 
Simulation of radiation driven fission gas diffusion in $\mathrm{UO} 2$, ThO2 and $\mathrm{PuO} 2$, J. Nucl. Mater. 481 (2016) 125-133, https://doi.org/10.1016/ j.jnucmat.2016.09.013.

[50] R. Bès, P. Martin, E. Vathonne, R. Delorme, C. Sabathier, M. Freyss, M. Bertolus, P. Glatzel, Experimental evidence of Xe incorporation in Schottky defects in UO2, Appl. Phys. Lett. 106 (2015) 114102, https://doi.org 10.1063/1.4914300.

[51] P.M. Martin, E. Vathonne, G. Carlot, R. Delorme, C. Sabathier, M. Freyss, P. Garcia, M. Bertolus, P. Glatzel, O. Proux, Behavior of fission gases in nuclear fuel: XAS characterization of Kr in UO2, J. Nucl. Mater. 466 (2015) 379-392 https://doi.org/10.1016/j.jnucmat.2015.08.019.

[52] D.A. Andersson, M.R. Tonks, L. Casillas, S. Vyas, P. Nerikar, B.P. Uberuaga, C.R. Stanek, Multiscale simulation of xenon diffusion and grain boundary segregation in UO2, J. Nucl. Mater. 462 (2015) 15-25, https://doi.org/ 10.1016/j.jnucmat.2015.03.019.

[53] W. Miekeley, F.W. Felix, Effect of stoichiometry on diffusion of xenon in UO2 J. Nucl. Mater. 42 (1972) 297-306, https://doi.org/10.1016/0022-3115(72) 90080-3.

[54] G.T. Lawrence, A review of the diffusion coefficient of fission-product rare gases in uranium dioxide, J. Nucl. Mater. 71 (1978) 195-218, https://doi.org/ 10.1016/0022-3115(78)90418-X

[55] A.D. Becke, Density-functional exchange-energy approximation with correct asymptotic behavior, Phys. Rev. 38 (1988) 3098-3100, https://doi.org/ 10.1103/PhysRevA.38.3098.

[56] J.P. Perdew, K. Burke, M. Ernzerhof, Generalized gradient approximation made simple, Phys. Rev. Lett. 77 (1996) 3865-3868, https://doi.org/10.1103 PhysRevLett.77.3865.

[57] B. Dorado, D.A. Andersson, C.R. Stanek, M. Bertolus, B.P. Uberuaga, G. Martin, M. Freyss, P. Garcia, First-principles calculations of uranium diffusion in uranium dioxide, Phys. Rev. B 86 (2012) 035110, https://doi.org/10.1103/ PhysRevB.86.035110.

[58] J.A. Turnbull, The distribution of intragranular fission gas bubbles in UO2 during irradiation, J. Nucl. Mater. 38 (1971) 203-212, https://doi.org/ 10.1016/0022-3115(71)90044-4.

[59] R.M. Cornell, An electron microscope examination of matrix fission-gas bubbles in irradiated uranium dioxide, J. Nucl. Mater. 38 (1971) 319-328, https://doi.org/10.1016/0022-3115(71)90061-4.

[60] C. Baker, The fission gas bubble distribution in uranium dioxide from high temperature irradiated sghwr fuel pins, J. Nucl. Mater. 66 (1977) 283-291, https://doi.org/10.1016/0022-3115(77)90117-9.

[61] S. Kashibe, K. Une, K. Nogita, Formation and growth of intragranular fission gas bubbles in UO2 fuels with burnup of 6-83 GWd/t, J. Nucl. Mater. 206 (1993) 22-34, https://doi.org/10.1016/0022-3115(93)90229-R.

[62] K. Nogita, K. Une, High resolution TEM of high burnup UO2 fuel, J. Nucl. Mater. 250 (1997) 244-249, https://doi.org/10.1016/S0022-3115(97)002821.

[63] K. Nogita, K. Une, High resolution TEM observation and density estimation of Xe bubbles in high burnup UO2 fuels, Nucl. Instrum. Methods Phys. Res. Sect. B Beam Interact. Mater. Atoms 141 (1998) 481-486, https://doi.org/10.1016/ S0168-583X(98)00040-8.

[64] H. Matzke, H. Blank, M. Coquerelle, K. Lassmann, I.L.F. Ray, C. Ronchi, C.T. Walker, Oxide fuel transients, J. Nucl. Mater. 166 (1989) 165-178, https://doi.org/10.1016/0022-3115(89)90187-6.

[65] L.E. Thomas, C.E. Beyer, L.A. Chariot, Microstructural analysis of LWR spent fuels at high burnup, J. Nucl. Mater. 188 (1992) 80-89, https://doi.org/ 10.1016/0022-3115(92)90457-V.

[66] S.E. Donnelly, J.H. Evans, Fundamental Aspects of Inert Gases in Solids, Springer, 2013.

[67] P. Garcia, P. Martin, G. Carlot, E. Castelier, M. Ripert, C. Sabathier, C. Valot F. D'Acapito, J.-L. Hazemann, O. Proux, V. Nassif, A study of xenon aggregates in uranium dioxide using X-ray absorption spectroscopy, J. Nucl. Mater. 352 (2006) 136-143, https://doi.org/10.1016/j.jnucmat.2006.02.047.

[68] I. Zacharie, S. Lansiart, P. Combette, M. Trotabas, M. Coster, M. Groos, Thermal treatment of uranium oxide irradiated in pressurized water reactor: swelling and release of fission gases, J. Nucl. Mater. 255 (1998) 85-91, https://doi.org/10.1016/S0022-3115(98)00039-7.

[69] K. UNE, S. KASHIBE, Fission gas release during post irradiation annealing of BWR fuels, J. Nucl. Sci. Technol. 27 (1990) 1002-1016, https://doi.org 10.1080/18811248.1990.9731285.

[70] M.S. Veshchunov, Modelling of grain face bubbles coalescence in irradiated UO2 fuel, J. Nucl. Mater. 374 (2008) 44-53, https://doi.org/10.1016 j.jnucmat.2007.06.021.

[71] M.S. Veshchunov, On the theory of fission gas bubble evolution in irradiated UO2 fuel, J. Nucl. Mater. 277 (2000) 67-81, https://doi.org/10.1016/S00223115(99)00136-1.

[72] J. Rest, An analytical study of gas-bubble nucleation mechanisms in uraniumalloy nuclear fuel at high temperature, J. Nucl. Mater. 402 (2010) 179-185, https://doi.org/10.1016/j.jnucmat.2010.05.022.

[73] P. Lösönen, On the behaviour of intragranular fission gas in UO2 fuel, J. Nucl. Mater. 280 (2000) 56-72, https://doi.org/10.1016/S0022-3115(00)00028-3.

[74] P. Garcia, G. Martin, C. Sabathier, G. Carlot, A. Michel, P. Martin, B. Dorado,
M. Freyss, M. Bertolus, R. Skorek, J. Noirot, L. Noirot, O. Kaitasov, S. Maillard, Nucleation and growth of intragranular defect and insoluble atom clusters in nuclear oxide fuels, Nucl. Instrum. Methods Phys. Res. Sect. B Beam Interact. Mater. Atoms 277 (2012) 98-108, https://doi.org/10.1016/ j.nimb.2011.12.031.

[75] C. Sabathier, L. Vincent, P. Garcia, F. Garrido, G. Carlot, L. Thome, P. Martin, C. Valot, In situ TEM study of temperature-induced fission product precipitation in UO2, Nucl. Instrum. Methods Phys. Res. Sect. B Beam Interact. Mater. Atoms 266 (2008) 3027-3032, https://doi.org/10.1016/ j.nimb.2008.03.158.

[76] A. Michel, Etude du comportement des gaz de fission dans le dioxyde d'uranium : mécanismes de diffusion, nucléation et grossissement de bulles, phdthesis, Université de Caen, 2011, https://tel.archives-ouvertes.fr/tel00691286/document. (Accessed 6 February 2018).

[77] A. Michel, C. Sabathier, G. Carlot, O. Kaïtasov, S. Bouffard, P. Garcia, C. Valot, An in situ TEM study of the evolution of Xe bubble populations in UO2, Nucl. Instrum. Methods Phys. Res. Sect. B Beam Interact. Mater. Atoms 272 (2012) 218-221, https://doi.org/10.1016/j.nimb.2011.01.069.

[78] G. Martin, P. Garcia, C. Sabathier, L. Van Brutzel, B. Dorado, F. Garrido, S. Maillard, Irradiation-induced heterogeneous nucleation in uranium dioxide, Phys. Lett. 374 (2010) 3038-3041, https://doi.org/10.1016/ j.physleta.2010.05.033.

[79] E. Moore, L. René Corrales, T. Desai, R. Devanathan, Molecular dynamics simulation of Xe bubble nucleation in nanocrystalline UO2 nuclear fuel, J. Nucl. Mater. 419 (2011) 140-144, https://doi.org/10.1016/ j.jnucmat.2011.08.052.

[80] P.V. Nerikar, D.C. Parfitt, L.A. Casillas Trujillo, D.A. Andersson, C. Unal S.B. Sinnott, R.W. Grimes, B.P. Uberuaga, C.R. Stanek, Segregation of xenon to dislocations and grain boundaries in uranium dioxide, Phys. Rev. B 84 (2011) 174105, https://doi.org/10.1103/PhysRevB.84.174105.

[81] S.T. Murphy, P. Fossati, R.W. Grimes, Xe diffusion and bubble nucleation around edge dislocations in UO2, J. Nucl. Mater. 466 (2015) 634-637, https://doi.org/10.1016/j.jnucmat.2015.09.007.

[82] G. Rossiter, Development of the enigma fuel performance code for whole core analysis and dry storage assessments, Nucl. Eng. Technol 43 (2011) 489-498, https://doi.org/10.5516/NET.2011.43.6.489.

[83] K. Lassmann, The TRANSURANUS code-past, present and future, ITU Act. Rep (2001) 16.

[84] L. NOIROT, MARGARET: an advanced mechanistic model of fission gas behavior in nuclear fuel, J. Nucl. Sci. Technol. 43 (2006) 1149-1160, https:// doi.org/10.1080/18811248.2006.9711207.

[85] D.A. Macinnes, I.R. Brearley, A model for the release of fission gas from reactor fuel undergoing transient heating, J. Nucl. Mater. 107 (1982) 123-132, https://doi.org/10.1016/0022-3115(82)90414-7.

[86] R.A. Jackson, C.R.A. Catlow, Trapping and solution of fission Xe in UO2, J. Nucl. Mater. 127 (1985) 161-166, https://doi.org/10.1016/0022-3115(85)903514.

[87] D.R. Olander, D. Wongsawaeng, Re-solution of fission gas - a review: Part I. Intragranular bubbles, J. Nucl. Mater. 354 (2006) 94-109, https://doi.org/ 10.1016/j.jnucmat.2006.03.010.

[88] R.S. Nelson, The stability of gas bubbles in an irradiation environment J. Nucl. Mater. 31 (1969) 153-161, https://doi.org/10.1016/0022-3115(69) 90189-5.

[89] D.C. Parfitt, R.W. Grimes, Predicting the probability for fission gas resolution into uranium dioxide, J. Nucl. Mater. 392 (2009) 28-34, https://doi.org/ 10.1016/j.jnucmat.2009.03.046.

[90] D. Schwen, M. Huang, P. Bellon, R.S. Averback, Molecular dynamics simulation of intragranular Xe bubble re-solution in UO2, J. Nucl. Mater. 392 (2009) 35-39, https://doi.org/10.1016/j.jnucmat.2009.03.037.

[91] M. Huang, D. Schwen, R.S. Averback, Molecular dynamic simulation of fission fragment induced thermal spikes in UO2: sputtering and bubble re-solution, J. Nucl. Mater. 399 (2010) 175-180, https://doi.org/10.1016/ j.jnucmat.2010.01.015.

[92] K. Govers, C.L. Bishop, D.C. Parfitt, S.E. Lemehov, M. Verwerft, R.W. Grimes, Molecular dynamics study of Xe bubble re-solution in UO2, J. Nucl. Mater. 420 (2012) 282-290, https://doi.org/10.1016/j.jnucmat.2011.10.010.

[93] P. Lösönen, Modelling intragranular fission gas release in irradiation of sintered LWR UO2 fuel, J. Nucl. Mater. 304 (2002) 29-49, https://doi.org 10.1016/S0022-3115(02)00856-5.

[94] M.V. Speight, W. Beere, Vacancy Potential and Void Growth on Grain Boundaries, vol. 9, 1975, pp. 190-1991.

[95] R.J. White, M. Tucker, A new mechanistic model for the calculation of fission gas release, in: Int. Top. Meet. Light Water React. Fuel Perform. West Palm Beach Fla. USA, 1994, pp. 17-21.

[96] J. Rest, The effect of irradiation-induced gas-atom re-solution on grainboundary bubble growth, J. Nucl. Mater. 321 (2003) 305-312, https:// doi.org/10.1016/S0022-3115(03)00303-9.

[97] D.R. Olander, P. Van Uffelen, On the role of grain boundary diffusion in fission gas release, J. Nucl. Mater. 288 (2001) 137-147, https://doi.org/10.1016/ S0022-3115(00)00725-X.

[98] T. Kogai, Modelling of fission gas release and gaseous swelling of light water 
reactor fuels, J. Nucl. Mater. 244 (1997) 131-140, https://doi.org/10.1016/ S0022-3115(96)00731-3.

[99] A.R. Massih, K. Forsberg, Calculation of grain boundary gaseous swelling in UO2, J. Nucl. Mater. 377 (2008) 406-408, https://doi.org/10.1016/ j.jnucmat.2008.03.011.

[100] G. Pastore, L. Luzzi, V. Di Marcello, P. Van Uffelen, Physics-based modelling of fission gas swelling and release in UO2 applied to integral fuel rod analysis, Nucl. Eng. Des. 256 (2013) 75-86, https://doi.org/10.1016/ j.nucengdes.2012.12.002.

[101] R. White, J.A. Turnbull, IFPE/CAGR-UOX-SWELL, Fuel swelling Data Obtained from the AGR/Halden Ramp Test Programme, 2006. http://inis.iaea.org/ Search/search.aspx?orig_q=RN:40064987. (Accessed 9 May 2016).

[102] J.H. Evans, The role of directed bubble diffusion to grain boundaries in postirradiation fission gas release from UO2: a quantitative assessment, J. Nucl. Mater. 238 (1996) 175-182, https://doi.org/10.1016/S0022-3115(96)004527.

[103] Y.-H. Koo, B.-H. Lee, D.-S. Sohn, Analysis of fission gas release and gaseous swelling in UO2 fuel under the effect of external restraint, J. Nucl. Mater. 280 (2000) 86-98, https://doi.org/10.1016/S0022-3115(00)00034-9.

[104] V.I. Tarasov, M.S. Veshchunov, Models for fuel porosity evolution in UO2 under various regimes of reactor operation, Nucl. Eng. Des. 272 (2014) 65-83, https://doi.org/10.1016/j.nucengdes.2014.02.016.

[105] M.S. Veshchunov, V.E. Shestak, An advanced model for intragranular bubble diffusivity in irradiated UO2 fuel, J. Nucl. Mater. 376 (2008) 174-180, https:// doi.org/10.1016/j.jnucmat.2008.01.026.

[106] P.C. Millett, M.R. Tonks, S.B. Biner, L. Zhang, K. Chockalingam, Y. Zhang, Phase-field simulation of intergranular bubble growth and percolation in bicrystals, J. Nucl. Mater. 425 (2012) 130-135, https://doi.org/10.1016/ j.jnucmat.2011.07.034.

[107] E.N. Hodkin, The ratio of grain boundary energy to surface energy of nuclear ceramics as determined from pore geometries, J. Nucl. Mater. 88 (1980) 7-14, https://doi.org/10.1016/0022-3115(80)90380-3.

[108] Y. Kim, Theoretical analysis of two-stage fission gas release processes: grain lattice and grain boundary diffusion, J. Nucl. Mater. 326 (2004) 97-105, https://doi.org/10.1016/j.jnucmat.2003.12.014.

[109] Y. Kim, C. Lee, Two-step two-stage fission gas release model, J. Nucl. Mater. 374 (2008) 431-436, https://doi.org/10.1016/j.jnucmat.2007.10.002.

[110] P.C. Millett, Y. Zhang, D.A. Andersson, M.R. Tonks, S.B. Biner, Random-walk Monte Carlo simulation of intergranular gas bubble nucleation in UO2 fuel, J. Nucl. Mater. 430 (2012) 44-49, https://doi.org/10.1016/ j.jnucmat.2012.06.049.

[111] H. Ibach, Physics of Surfaces and Interfaces, Springer, 2006.

[112] J. Rest, Z. Insepov, B. Ye, D. Yun, A multiscale method for the analysis of defect behavior in Mo during electron irradiation, Comput. Mater. Sci. 93 (2014) 169-177, https://doi.org/10.1016/j.commatsci.2014.06.044.

[113] S. Hu, C.H. Henager Jr., H.L. Heinisch, M. Stan, M.I. Baskes, S.M. Valone, Phasefield modeling of gas bubbles and thermal conductivity evolution in nuclear fuels, J. Nucl. Mater. 392 (2009) 292-300, https://doi.org/10.1016/ j.jnucmat.2009.03.017.

[114] P.C. Millett, A. El-Azab, D. Wolf, Phase-field simulation of irradiated metals: Part II: gas bubble kinetics, Comput. Mater. Sci. 50 (2011) 960-970, https:// doi.org/10.1016/j.commatsci.2010.10.032.

[115] P.C. Millett, M.R. Tonks, S.B. Biner, Grain boundary percolation modeling of fission gas release in oxide fuels, J. Nucl. Mater. 424 (2012) 176-182, https:// doi.org/10.1016/j.jnucmat.2012.03.006.

[116] Y. Li, S. Hu, R. Montgomery, F. Gao, X. Sun, Phase-field simulations of intragranular fission gas bubble evolution in UO2 under post-irradiation thermal annealing, Nucl. Instrum. Methods Phys. Res. Sect. B Beam Interact. Mater. Atoms 303 (2013) 62-67, https://doi.org/10.1016/ j.nimb.2012.11.028.

[117] J.P. Simmons, Y. Wen, C. Shen, Y.Z. Wang, Microstructural development involving nucleation and growth phenomena simulated with the Phase Field method, Mater. Sci. Eng., A 365 (2004) 136-143, https://doi.org/10.1016/ j.msea.2003.09.019.

[118] A.M. Jokisaari, C. Permann, K. Thornton, A nucleation algorithm for the coupled conserved-nonconserved phase field model, Comput. Mater. Sci. 112 (Part A) (2016) 128-138, https://doi.org/10.1016/ j.commatsci.2015.10.009.

[119] D. Schwen, L.K. Aagesen, J.W. Peterson, M.R. Tonks, Rapid multiphase-field model development using a modular free energy based approach with automatic differentiation in MOOSE/MARMOT, Comput. Mater. Sci. 132 (2017) 36-45, https://doi.org/10.1016/j.commatsci.2017.02.017.

[120] S. Valin, A. Mocellin, G. Eminet, S. Ravel, J.-C. Joubert, Modelling the behaviour of intergranular fission gas during out-of-pile annealing, in: Prodeedings Semin. Fission Gas Behav. Water React. Fuels, 2000.

[121] W. Beeré, G.L. Reynolds, The morphology and growth rate of interlinked porosity in irradiated UO2, J. Nucl. Mater. 47 (1973) 51-57, https://doi.org/ 10.1016/0022-3115(73)90185-2.

[122] J.A. Turnbull, M.O. Tucker, Swelling in UO2 under conditions of gas release, Philos. Mag. 30 (1974) 47-63, https://doi.org/10.1080/14786439808206532.

[123] M.O. Tucker, J.A. Turnbull, The morphology of interlinked porosity in nuclear fuels, Proc. R. Soc. Lond. Math. Phys. Eng. Sci. 343 (1975) 299-314, https:// doi.org/10.1098/rspa.1975.0067.

[124] M.O. Tucker, The transfer of fission gas between grain faces and edges in UO2, J. Nucl. Mater. 75 (1978) 282-287, https://doi.org/10.1016/00223115(78)90009-0.

[125] M.O. Tucker, Grain boundary porosity and gas release in irradiated UO2, Radiat. Eff. 53 (1980) 251-255, https://doi.org/10.1080/ 00337578008207120.

[126] M. Mogensen, C.T. Walker, I.L.F. Ray, M. Coquerelle, Local fission gas release and swelling in water reactor fuel during slow power transients, J. Nucl. Mater. 131 (1985) 162-171, https://doi.org/10.1016/0022-3115(85)904556.

[127] I. Zacharie, S. Lansiart, P. Combette, M. Trotabas, M. Coster, M. Groos, Thermal treatment of uranium oxide irradiated in pressurized water reactor: swelling and release of fission gases, J. Nucl. Mater. 255 (1998) 85-91, https://doi.org/10.1016/S0022-3115(98)00039-7.

[128] R.J. White, S.B. Fisher, P.M.A. Cook, R. Stratton, C.T. Walker, I.D. Palmer, Measurement and analysis of fission gas release from BNFL's SBR MOX fuel, J. Nucl. Mater. 288 (2001) 43-56, https://doi.org/10.1016/S0022-3115(00) 00591-2.

[129] S.B. Fisher, R.J. White, P.M.A. Cook, S. Bremier, R.C. Corcoran, R. Stratton, C.T. Walker, P.K. Ivison, I.D. Palmer, Microstructure of irradiated SBR MOX fuel and its relationship to fission gas release, J. Nucl. Mater. 306 (2002) 153-172, https://doi.org/10.1016/S0022-3115(02)01247-3.

[130] G.L. Reynolds, G.H. Bannister, Examination of neutron-irradiated UO2 using the scanning electron microscope, J. Mater. Sci. 5 (1970) 84-85, https:// doi.org/10.1007/BF02427186.

[131] J.C. Killeen, The effect of additives on the irradiation behaviour of UO2 J. Nucl. Mater. 58 (1975) 39-46, https://doi.org/10.1016/0022-3115(75) 90164-6.

[132] M.O. Tucker, A simple description of interconnected grain edge porosity, J. Nucl. Mater. 79 (1979) 199-205, https://doi.org/10.1016/0022-3115(79) 90447-1.

[133] P.C. Millett, Percolation on grain boundary networks: application to fission gas release in nuclear fuels, Comput. Mater. Sci. 53 (2012) 31-36, https:// doi.org/10.1016/j.commatsci.2011.09.025.

[134] D. Sabogal-Suárez, J. David Alzate-Cardona, E. Restrepo-Parra, Fission gas bubble percolation on crystallographically consistent grain boundary networks, J. Nucl. Mater. 475 (2016) 81-86, https://doi.org/10.1016/ j.jnucmat.2016.03.031.

[135] M.J.F. Notley, J.R. MacEwan, Stepwise release of fission gas from $\mathrm{UO}_{2}$ fuel, Nucl. Technol. 2 (1966) 477-480.

[136] R.M. Carroll, J.G. Morgan, R.B. Perez, O. Sisman, Fission density, burnup, and temperature effects on fission-gas release from $\mathrm{UO}_{2}$, Nucl. Sci. Eng. 38 (1969) $143-155$.

[137] I.J. Hastings, A.D. Smith, P.J. Fehrenbach, T.J. Carter, Fission gas release from power-ramped UO2 fuel, J. Nucl. Mater. 139 (1986) 106-112, https://doi.org/ 10.1016/0022-3115(86)90028-0.

[138] C.T. Walker, P. Knappik, M. Mogensen, Concerning the development of grain face bubbles and fission gas release in UO2 fuel, J. Nucl. Mater. 160 (1988) 10-23, https://doi.org/10.1016/0022-3115(88)90003-7.

[139] K. Une, K. Nogita, S. Kashibe, M. Imamura, Microstructural change and its influence on fission gas release in high burnup UO2 fuel, J. Nucl. Mater. 188 (1992) 65-72, https://doi.org/10.1016/0022-3115(92)90455-T.

[140] R.M. Carroll, O. Sisman, In-pile fission-gas release from single-crystal $\mathrm{UO}_{2}$ Nucl. Sci. Eng. 21 (1965) 147-158.

[141] T. Barani, E. Bruschi, D. Pizzocri, G. Pastore, P. Van Uffelen, R.L. Williamson, L. Luzzi, Analysis of transient fission gas behaviour in oxide fuel using BISON and TRANSURANUS, J. Nucl. Mater. 486 (2017) 96-110, https://doi.org/ 10.1016/j.jnucmat.2016.10.051.

[142] C. Wise, Recoil release of fission products from nuclear fuel, J. Nucl. Mater. 136 (1985) 30-47, https://doi.org/10.1016/0022-3115(85)90028-5.

[143] B.J. Lewis, Fission product release from nuclear fuel by recoil and knockout, J. Nucl. Mater. 148 (1987) 28-42, https://doi.org/10.1016/0022-3115(87) 90515-0.

[144] A.D. Appelhans, J.A. Turnbull, in: Gaithersburg, MD, 1980

[145] I.J. Hastings, C.E.L. Hunt, J.J. Lipsett, Release of short-lived fission products from UO2 fuel: effects of operating conditions, J. Nucl. Mater. 130 (1985) 407-417, https://doi.org/10.1016/0022-3115(85)90327-7.

[146] I. Hastings, C. Hunt, J. Lipsett, R. MacDonald, Behaviour of short-lived fission products within operating UO 2 fuel elements, Res. Mech. 6 (1983) 167.

[147] E. Rothwell, The release of kr85 from irradiated uranium dioxide on postirradiation annealing, J. Nucl. Mater. 5 (1962) 241-249, https://doi.org/ 10.1016/0022-3115(62)90105-8.

[148] G. Ducros, Y. Pontillon, P.P. Malgouyres, Synthesis of the VERCORS experimental programme: separate-effect experiments on Fission Product release, in support of the PHEBUS-FP programme, Ann. Nucl. Energy 61 (2013) 75-87, https://doi.org/10.1016/j.anucene.2013.02.033.

[149] J. Rest, S.M. Gehl, The mechanistic prediction of transient fission-gas release from LWR fuel, Nucl. Eng. Des. 56 (1980) 233-256, https://doi.org/10.1016/ 0029-5493(80)90189-2.

[150] P. Chakraborty, M.R. Tonks, G. Pastore, Modeling the influence of bubble pressure on grain boundary separation and fission gas release, J. Nucl. Mater. 
452 (2014) 95-101, https://doi.org/10.1016/j.jnucmat.2014.04.023.

[151] W. Hering The kwu fission gas release model for lwr fuel rods, J. Nucl. Mater. 114 (1983) 41-49, https://doi.org/10.1016/0022-3115(83)90071-5.

[152] Y.-H. Koo, B.-H. Lee, D.-S. Sohn, Cosmos: a computer code to analyze LWR UO2 and MOX fuel up to high burnup, Ann. Nucl. Energy 26 (1999) 47-67, https://doi.org/10.1016/S0306-4549(98)00033-4.

[153] L.C. Bernard, J.L. Jacoud, P. Vesco, An efficient model for the analysis of fission gas release, J. Nucl. Mater. 302 (2002) 125-134, https://doi.org/10.1016/
S0022-3115(02)00793-6.

[154] P. Van Uffelen, A. Schubert, J. van de Laar, C. GylHori, Development of a transient fission gas release model for TRANSURANUS, in: Water React. Fuel Perform. Meet, 2008.

[155] G. Pastore, D. Pizzocri, J. Hales, S. Novascone, D. Perez, B. Spencer R. Williamson, P. Van Uffelen, L. Luzzi, Modelling of transient fission gas behaviour in oxide fuel and application to the BISON code, in: Enlarg. Halden Programme Group Meet. Røros Nor, 2014. 